SOCIAL SCIENCE RESEARCH

\author{
Paul Heidhues * \\ Nicolas Melissas ** \\ Equilibria in a Dynamic Global Game: \\ The Role of Cohort Effects \\ * WZB - Wissenschaftszentrum Berlin \\ ** University of Leicester
}

SP I| $2003-08$

July 2003

ISSN Nr. $0722-6748$

Research Area

Markets and Political Economy

Research Unit

Competitiveness and Industrial Change
Forschungsschwerpunkt

Markt und politische Ökonomie

Abteilung

Wettbewerbsfähigkeit und industrieller Wandel 
Zitierweise/Citation:

Paul Heidhues and Nicolas Melissas, Equilibria in a Dynamic Global Game: The Role of Cohort Effects, Discussion Paper SP II 2003 - 08, Wissenschaftszentrum Berlin, 2003.

Wissenschaftszentrum Berlin für Sozialforschung gGmbH, Reichpietschufer 50, 10785 Berlin, Germany, Tel. (030) 25491 - 0 Internet: www.wz-berlin.de 


\title{
ABSTRACT
}

\section{Equilibria in a Dynamic Global Game: The Role of Cohort Effects*}

\author{
by Paul Heidhues and Nicolas Melissas
}

\begin{abstract}
We introduce strategic waiting in a global game setting with irreversible investment. Players can wait in order to make a better informed decision. We allow for cohort effects and discuss when they arise endogenously in technology adoption problems with positive contemporaneous network effects. Formally, cohort effects lead to intra-period network effects being greater than inter-period network effects. Depending on the nature of the cohort effects, the dynamic game may or may not satisfy dynamic strategic complementarity. If it does, our model has a unique rationalizable outcome. Otherwise, there exists parameter values for which multiple equilibria arise because player have a strong incentive to invest at the same point in time others do.
\end{abstract}

Keywords: Global Game, Strategic Waiting, Coordination, Strategic

Complementarities, Period-specific Network Effects, Equilibrium Selection.

JEL Classification: C72, C73, D82, D83.

* We want to thank George-Marios Angeletos, Helmut Bester, Estelle Cantillon, Frank Heinemann, Christian Hellwig, Larry Karp, Tobias Kretshmer, In Ho Lee, and Robin Mason for helpful discussions. We would also like to thank seminar participants at the Free University Berlin, IAE (Barcelona), MIT, University of Pittsburgh, and at the CEPRconference on The Evolution of Market Structure in Network Industries (Brussels 2002) for comments. We thank the European Union for providing financial support through the TMR network on network industries (Contract number FMRX-CT98-0203). This paper was completed while the first author visited the Department of Economics at MIT, whose hospitality he gratefully acknowledges.

Contact Information:

Paul Heidhues, Wissenschaftszentrum Berlin für Sozialforschung (WZB), Reichpietschufer 50, 10785 Berlin, Germany (heidhues@wz-berlin.de).

Nicolas Melissas, University of Leicester, University Road, Leicester, LE1 7RH, UK (ndm9@leicester.ac.uk). 


\section{Gleichgewichte in einem Dynamischen Globalen Spiel: Die Rolle von Kohorteneffekten}

Koordinationsspiele haben typischerweise multiple Nashgleichgewichte mit sich selbsterfüllenden Erwartungen. Die Theorie der globalen Spiele führt Unsicherheit und private Informationen in statischen Koordinationsspielen ein und zeigt die Bedingungen auf, unter denen dies zu einem eindeutigen Gleichgewicht führt. In diesem Beitrag untersuchen wir ein Zweiperiodenspiel, in welchem die Spieler eine irreversible Investitionsentscheidung mit einer positiven Netwerkexternalität treffen. In der ersten Periode wählen die Spieler, ob sie sofort investieren oder auf bessere Informationen über das Projekt warten. Wir zeigen, dass Kohorteneffekte bei Technologiewahlproblemen mit positiven Netzwerkexternalitäten auftreten und untersuchen ihre Auswirkungen. Kohorteneffekte führen dazu, dass die Intraperioden-Netzwerkeffekte größer sind als die Interperioden-Netzwerkeffekte. Aus technischer Sicht bestimmen die Kohorteneffekte, ob das globale Spiel die Eigenschaft der dynamischen strategischen Komplemantarität erfüllt. Diese Eigenschaft wiederum impliziert, dass unser Modell eine eindeutige rationalisierbare Lösung hat. Ist diese Eigenschaft nicht erfüllt, so hat jeder Spieler einen hohen Anreiz zum gleichen Zeitpunkt wie die andern Spieler zu investieren. In diesem Fall exstieren Parameterwerte für welche unser Spiel multiple Nashgleichgewichtslösungen hat. 


\section{Introduction}

In many economic situations, the optimal action of an economic agent is complementary to the actions undertaken by other agents. For example, a consumer's payoff from buying a computer software is typically increasing in the number of other consumers who also use that software. Or, think of a consumer who decides to buy a durable consumption good such as a car. As more consumers buy this brand of car, more repair shops will have the know-how and spare parts to repair the car quickly. ${ }^{1}$ Models of situations in which the agents' optimal actions are complementary to each other are often plagued by multiple equilibria with selffullfilling beliefs: If a player expects the other players to buy the software, then it is in her best interest to buy it as well. If a player expects the other players not to acquire the software, she wants to refrain from buying. This multiplicity result is annoying from an economic-policy point of view. Without an adequate theory of equilibrium selection, one cannot use these theories to predict the market outcome. How then does one judge, for example, whether policies to subsidize/tax the adoption of information technology should be implemented? How does one predict the market power of firms who sell their products in markets with network externalities?

For two-player coordination games, Carlsson and van Damme (1993), henceforth $\mathrm{CvD}$, developed an equilibrium selection theory, which was adopted to a coordination problem with a continuum of players by Morris and Shin (1998). CvD assume that the agents' payoffs depend on the action chosen by the other agent in the economy and some unknown economic fundamental summarized by the state of the world $\theta$. Agents receive different signals about $\theta$, which generate beliefs about the state of the world and a hierarchy of higher order beliefs (beliefs about the other agent's beliefs, beliefs about the other agent's beliefs about his beliefs, etc...). ${ }^{2} \mathrm{CvD}$ called this incomplete information game a global game and showed

\footnotetext{
${ }^{1}$ Complementarity of optimal actions is also a key ingredient of many models of macroeconomic coordination failures such as currency crises, debt crises, bank runs, financial crashes, and Keynestype underemployment (Obstfeld (1996), Cole and Kehoe (1996), Diamond and Dybvig (1983), Bryant (1983)). Milgrom and Roberts (1990) discuss other examples of games with strategic complementarities such as R\&D competition, oligopoly, coordination in teams, arms races, and pretrial bargaining.

${ }^{2}$ Carlsson and van Damme's work is based on the insight developed in Rubinstein's (1989) famous electronic mail game, in which he illustrated that the risk-dominated equilibrium of the common knowledge game is selected as the unique equilibrium in the absence of common knowledge.
} 
that if the potential type space is rich enough, the game has a unique equilibrium. ${ }^{3}$

Thus, the global game framework enables researchers to base policy recommendations on theory that predicts behavior in coordination games. It has been applied to a wide variety of contexts within a static framework. ${ }^{4}$ In reality, however, many economic coordination problems are essentially dynamic. Players can always postpone their investment decisions in order to make a better informed decision at a later point in time. In this paper, we investigate conditions under which the global game approach can be extended to model dynamic technology adoption problems.

To address this question, we build a dynamic global game. We consider a continuum of investors, who have the opportunity to engage in a risky investment project in either of two periods. Investments are irreversible. Payoffs depend positively on the realization of a random variable, which we refer to as the fundamental, and on the mass of investors. All players receive some noisy private information concerning the realization of the fundamental. For very high signals, it is a dominant strategy to invest immediately and for very low signals it is a dominant strategy not to invest. For intermediate signals, a player's optimal behavior depends on her beliefs about how other investors act. If a player decides to wait, she gets a more informative signal concerning the realization of the fundamental at the cost of foregone profits. Our signaling technology is simple in the sense that we assume a uniform distribution of period-one signals. Moreover, we assume that each player at time two can either receive good or bad news. Our signaling technology ensures that the posterior about the fundamental is distributed uniformly around a player's signal in both periods. This simplifies the computation of our equilibrium strategies and permits us to get closed-form solutions. It also enables us to

\footnotetext{
${ }^{3}$ We refer to any binary action game that is characterized by strategic complementarity, incomplete information, and in which for some types it is a dominant strategy to adopt one action while for others it is a dominant strategy to adopt the other as a global game. That heterogeneity of agents can lead to a unique equilibrium in situations in which the agents actions are complementary to each other was shown earlier by Postlewaite and Vives (1987) in a bankrun model. One novel insight of the global game approach is that lack of common knowledge about the distribution of types often suffices to select a unique equilibrium even if heterogeneity in first-order beliefs is small and payoffs are identical. For a comprehensive survey of the global game literature, see Morris and Shin (2001). For an extension of the global game approach to many action games, see Frankel, Morris and Pauzner (2002).

${ }^{4}$ It is used, for example, to model currency crises (Morris and Shin (1998), Corsetti et al. (2000)), bank runs (Goldstein and Pauzner (2000), Rochet and Vives (2000)) and car-dealer markets (Dönges and Heinemann (2000)).
} 
work with a flexible dynamic payoff structure in which a player's gain of investing not only depends on the total mass of players who invest, but also on when the other players invest. We say that our payoffs exhibit an early (late) mover cohort effect if the early (late) adopters enjoy more network benefits from the other early (late) adopters than from the late (early) ones. Four main results emerge from our analysis.

First, we show that cohort effects can arise endogenously in a dynamic set-up with contemporaneous network effects. We discuss three archetypical technology adoption problems. In the first, which we refer to as the fixed horizon technology adoption problem $(\mathrm{FH})$, players decides to adopt a technology that becomes obsolete at some given point in time. In the interim period in which late movers have not invested yet, early movers in this example are subject to a contemporaneous network effect, which depends on the mass of early movers only. For late investors, however, the network benefit in any period depends on the total mass of players who have adopted the technology, which includes early as well as late movers. This example is thus characterized by an early mover cohort effect and is void of any late mover cohort effect. In the second example, which we refer to as (FL), players invest into a technology that has a fixed lifespan of $T$ periods before becoming obsolete. Here, not only the above early mover cohort effect is present but also a late mover cohort effect. The reason is that the early movers technology becomes obsolete while late movers are still using the technology. But then after the early movers technology has become obsolete, late movers contemporaneous network effect depends only on the mass of late adopters. In the last example, which we refer to as (PI), players pledge to invest before the technology becomes available. As the technology becomes available to all players at the same point in time, there is neither an early nor a late mover cohort effect.

We next introduce a condition on ex-post payoffs called dynamic strategic complementarity, which ensures that a unique rationalizable outcome exists. Call both a change from not investing to investing late and a change from investing late to investing early a move to a higher action. Dynamic strategic complementarity implies that as a higher percentage of the population takes a higher action, it becomes weakly more profitable to take a higher action. For example, it requires that as more players invest late rather than not at all, it becomes weakly more profitable to invest early. Our second result shows that a technology adoption problem that exhibits contemporaneous strategic complementarity does not necessarily exhibit 
dynamic strategic complementarity. In particular, dynamic strategic complementarity requires that there is no late mover cohort effect and it is thus violated by the FL problem discussed above. The other examples given, however, satisfy dynamic strategic complementarity.

Our third main result proves that dynamic strategic complementarity indeed implies the existence of a unique rationalizable outcome. We start by observing that active players who have a "very high" second-period signal always want to invest, ${ }^{5}$ since they believe that the fundamental is so good that investing is profitable no matter what actions the other players choose. Now consider a player who has an "extremely high" first-period signal so that she foresees that her second-period signal will be very high even if she gets bad news. Obviously, she strictly benefits from investing immediately and saving the waiting costs if she expect no other player to invest.

Now consider a player who has a "high" but not an "extremely high" first-period signal. If she expects no other player to invest in either priod, then she would prefer to refrain from investing as well. Given her signal, it is equally likely that the other players received a higher or lower signal than herself. Therefore, in equilibrium, she cannot expect no other player to invest. As her signal is "high," her knowledge that everyone with an extremely high signal invests early and everyone with a very high signal invests late induces her to invest early as well. Similar, the knowledge that everyone with an extremely high signal invests early and all active players with a very high signal invest late, gives active players with a high but not very high signal a strict incentive to invest in the second period. This will, in turn, convince players with slightly less favorable signals to also invest, etc... . This process of iterative elimination of dominated strategies ends at some cutoff vector $\left(k_{1}, k_{2}\right)$. At this cutoff vector a player with a first-period signal equal to $k_{1}$ is indifferent between investing immediately and waiting if she expects all players to invest in period $t$ whenever they receive a signal above $k_{t}$ and refrain from investing otherwise. Similar, a player with a second-period signal equal to $k_{2}$ who has the above expectation about the other players' behavior is indifferent between investing and not investing. Mirroring the above argument, because it is a dominant strategy not to invest for very low signals, players with low signals refrain from investing. Iteratively eliminating players for whom it is a dominant strategy not to invest, there is a critical cutoff vector $\left(k_{1}, k_{2}\right)$ such that a player

\footnotetext{
${ }^{5}$ With "active" we mean that a player did not invest at time one.
} 
refrains from investing in period $t$ whenever she has a signal below $k_{t}$. The proof is then completed by arguing that these cutoff vectors give rise to symmetric switching equilibria and that if payoffs satisfy dynamic strategic complementarity, then there exists a unique symmetric switching equilibrium.

Fourth, we characterize symmetric switching equilibria for a wide range of parameter values. We find closed form solutions for all economic examples introduced earlier. For the economic interpretations that satisfy dynamic strategic complementarity, we thus characterized the unique symmetric switching equilibrium, which allows us to do comparative statics. We show, for example, that as players become more patient, immediate investment activity can increase while late investment activity decreases in the FH example. The characterization also allows us to illustrate why multiple equilibria can arise if dynamic strategic complementarity is violated. In essence, if dynamic strategic complementarity is violated, then players have an incentive to invest at the same point in time at which other players invest. If this incentive is strong enough, it gives rise to self-fullfilling expectations according to which some players invest late if and only if they believe other players to invest late. We also give a necessary and sufficient condition for the fixed lifespan interpretation to have a unique equilibrium within the class of symmetric switching equilibria. Thus, at least within the class of symmetric switching equilibria, dynamic strategic complementarity is not necessary for the uniqueness of equilibrium.

This is not the only paper to introduce dynamic elements in a global game. Chamley (1999) studies a dynamic global game in which there is uncertainty about distribution of the investment costs in society. The distribution of investment costs evolves stochastically through time. Players use the observed previous aggregate behavior together with their knowledge of equilibrium strategies, to update their beliefs about the state of the world. As long as their is sufficient heterogeneity in the population, each period can be analyzed similar to a static global game and, hence, there is a unique equilibrium. ${ }^{6}$ A key difference to our paper is that there

\footnotetext{
${ }^{6}$ Recall that in a static global game set-up, if players observe a public and a private signal and the public signal is sufficiently precise, then multiple equilibria prevail as players can use the public signal as a coordination device (see Hellwig (2002)). In Chamley's model, if the population is sufficiently heterogenous, the inferences players draw based on past observed behavior are less precise. Because the parameter of the distribution of investment costs changes only slowly over time, heterogeneity is needed to rule out equilibria in which players ignore their private signals and use their common equilibrium knowledge of the distribution of the states of the world as a "public signal" to coordinate behavior.
} 
is a new population of players in every period. Thus, players cannot choose when to invest. ${ }^{7}$

Morris and Shin (1999) study the onset of currency crises using a dynamic global game in which the fundamental follows a Markov process. As long as their has been no successful attack, all players chooses whether or not to attack in every period. Players observe the past realizations of the fundamental and a private signal regarding the current realization. If the private signal is sufficiently precise, each period can be analyzed as a static global game and the model has a unique equilibrium. ${ }^{8}$ In contrast to our model, investments are not irreversible. ${ }^{9}$

Dasgupta (2001) introduces elements of strategic waiting in a global game with irreversible investment. Players can invest in two periods. If a player delays, she observes a noisy signal about the past economic activity at the cost of foregone profits. Dasgupta shows that his game, under some additional assumptions on the prior distribution and the signaling technology, is characterized by a unique equilibrium within the class of switching strategies. The main difference between our paper and Dasgupta (2001) is that we investigate cohort effects, which are not

\footnotetext{
${ }^{7}$ Burdzy, Frankel, and Pauzner (2001) investigate a complete information dynamic model in which the state evolves stochastically through time and in each period a continuum of players is randomly matched to play a $2 \times 2$ game with strategic complementarities. Under the assumptions that (i) in some states of the world playing one action is dominant while in others the other is dominant and (ii) that in each period a player has only a small chance of revising her action, they show that players choose to play the risk-dominant equilibrium in the limit as revision opportunities arrive quickly. Frankel and Pauzner (2000) use a similar setup to investigate a model of sectoral choice in which there are external increasing returns and show that there is a unique equilibrium even if frictions are nonnegligible. In contrast to our paper, players cannot engage in strategic waiting in either of these papers. Also, the arguments in both papers rely on only a small set of player being able revise their action at any given point in time, while in our paper all players can move at the same time.

${ }^{8}$ Technically, however, Morris and Shin focus on Markov strategies only when proving their result. Intuitively, this is justified because the past realization of the fundamental is common knowledge and hence there is no incentive to engage in social learning through observing the rivals' past behavior.

${ }^{9}$ Toxvaerd (2002) analyzes merger waves in which investment are irreversible using essentially the same observability conditions and signaling assumptions as in Morris and Shin (1999). He assumes that potential targets are scarce, the potential benefits of mergers are uncertain, and that there are positive rents from takeovers. Because increased merger activity by rivals increases the risk of not being able to engage in a profitable merger, there is a negative externality in the takeover game. This leads to strategic complementarity in the waiting decision. Toxvaerd shows that if the private signals are sufficiently precise, there exists a unique perfect Bayesian equilibrium within the class of (Markovian) symmetric switching strategies.
} 
present in his model in which payoffs depend only on whether a sufficient number of players invest in either period. Another difference is that in his model one wants to delay to engage in social learning, while in our model a player delays to obtain a more precise signal. Furthermore, when establishing uniqueness in the absence of cohort effects, we do not restrict attention to switching strategies only.

The remainder of this paper is organized as follows. In section 2, we introduce our formal model. In section 3, we relate the parameters of our model to different economic environments. In section 4, we analyze equilibrium behavior in our model. We first state our definition of dynamic strategic complementarity and show that, when our payoffs satisfy that condition, our model features an essentially unique outcome (subsection 4.1). Next, in subsection 4.2, we provide closed-form solutions for two important types of symmetric switching equilibria and we analyze when (i.e. for which values of our exogenous parameters) our model has multiple equilibria. In section 4.3 we detail on the basis of two (pedagogical) examples the driving force behind our multiplicity result. Section 5 presents some comparative static results when our model features an essentially unique equilibrium. Final comments are summarized in section 6 . All proofs can be found in the appendix.

\section{The model}

Assume a continuum of risk-neutral players with mass one that are indexed along the line $[0,1]$. All players have the opportunity to undertake one risky investment project. Investments are irreversible. A player can invest at time one, at time two, or can decide not to invest at all. If player $i$ decides to invest at time one, she gets a utility $U_{1}^{i}$ equal to:

$$
U_{1}^{i}=\theta+n_{1}+\alpha n_{2}-1,
$$

where $n_{1}\left(n_{2}\right)$ denotes the mass of players who invest at time one (two). The state of the world $\theta$ is randomly drawn from a uniform distribution along the entire real line. A period-two investor enjoys a utility equal to:

$$
U_{2}^{i}=\tau\left(\theta+\gamma n_{1}+n_{2}-1-\Delta\right) .
$$

If player $i$ decides not to invest in both periods, she gets zero. Throughout, we assume that $\tau, \alpha, \gamma \in[0,1]$ and that $\Delta \geq 0$. We postpone the discussion of the economic motivation for our payoff structure until the next section. 
All players possess a private and imperfect signal concerning the realized state of the world. Formally, player $i$ 's first-period signal, $s_{1}^{i}$, equals:

$$
s_{1}^{i}=\theta+\epsilon_{2}^{i}+\epsilon_{1}^{i},
$$

where $\epsilon_{2}^{i} \sim U[-\epsilon, \epsilon]$ and $\epsilon_{1}^{i} \in\{-\epsilon, \epsilon\}$. The prior probability that $\epsilon_{1}^{i}=-\epsilon$ equals $\frac{1}{2}$. $\epsilon_{2}^{i}$ and $\epsilon_{1}^{i}$ are independently distributed. Player $i$ 's second-period signal, $s_{2}^{i}$, equals:

$$
s_{2}^{i}=\theta+\epsilon_{2}^{i} .
$$

The first- (and second-) period errors $\epsilon_{1}^{i}\left(\epsilon_{2}^{i}\right)$ are uncorrelated among the different players.

Note that our model possesses some "desirable" features that highly simplify the computation of our equilibrium strategies and enable a direct comparison with the static counterparts of our model. First, note that $s_{1}^{i}$ is constructed by adding noise to $s_{2}^{i}$. In statistical terms, this means that $s_{2}^{i}$ is a sufficient statistic for $s_{1}^{i}$. In particular, this implies that $E\left(\theta \mid s_{2}^{i}, s_{1}^{i}\right)=E\left(\theta \mid s_{2}^{i}\right)$. Second, we know that $s_{2}^{i}=\theta+\epsilon_{2}^{i}$. This last equality can be rewritten as $\theta=s_{2}^{i}-\epsilon_{2}^{i}$. Hence, $\theta \mid s_{2}^{i} \sim U\left[s_{2}^{i}-\epsilon, s_{2}^{i}+\epsilon\right]$, and $E\left(\theta \mid s_{2}^{i}\right)=s_{2}^{i}$. Similar, one has $\theta \mid s_{1}^{i} \sim U\left[s_{1}^{i}-2 \epsilon, s_{1}^{i}+2 \epsilon\right]$, and $E\left(\theta \mid s_{1}^{i}\right)=s_{1}^{i}$. That is the errors are uniformly distributed in both periods. This ensures that if players were allowed to invest either only in the first or only in the second period, then our game would be characterized by a unique equilibrium in switching strategies. $^{10}$

The timing of the game we study is as follows:

0 ) Nature chooses $\theta$. All players receive their first-period signals.

1) All players simultaneously decide whether to invest or wait.

2) Player $i$ observes whether $\epsilon_{1}^{i}=\epsilon$ or $\epsilon_{1}^{i}=-\epsilon$ but not $n_{1}$. If she did not invest at time one, she decides whether or not to do so at time two.

3) All players receive their payoffs and the game ends.

Each player's time-one action space, $A^{1}$, equals $\{$ invest, not invest $\}$. Player $i$ 's timetwo action space, $A^{2}$, equals \{invest, not invest $\}$ if $a_{1}^{i}=$ not invest, and equals \{not invest $\}$ if $a_{1}^{i}=$ invest. Player $i$ 's observable history at time one is $H_{1}^{i}=\left\{s_{1}^{i} \mid s_{1}^{i} \in \Re\right\}$ and at time two is $H_{2}^{i}=\left\{\left(s_{1}^{i}, s_{2}^{i}\right) \mid s_{1}^{i} \in \Re \wedge s_{2}^{i} \in\left\{s_{1}^{i}-\epsilon, s_{1}^{i}+\epsilon\right\}\right\} \times A^{1}$. Let $\sigma^{i}=\left(\sigma_{1}^{i}, \sigma_{2}^{i}\right)$

\footnotetext{
${ }^{10}$ Using a similar argument to Morris and Shin (2001), this extends to an essentially unique equilibrium in rationalizable strategies.
} 
denote player $i$ 's behavioral strategy, where $\sigma_{1}^{i}\left(s_{1}^{i}\right)$ represents the probability with which player $i$ invests at time one given her first period signal and $\sigma_{2}^{i}\left(s_{1}^{i}, s_{2}^{i}\right)$ represents the probability with which player $i$ invests at time two given $\left(s_{1}^{i}, s_{2}^{i}\right)$ and that she did not invest in the first period. (Trivially, a player cannot invest in the second period if $a_{1}^{i}=$ invest, i.e. if she already invested in the first period.) We denote a strategy profile by $\sigma$.

Frequently, we will refer to symmetric switching strategies. A strategy profile is a symmetric switching strategy profile if it can be parameterized by a single vector $k \equiv\left(k_{1}, k_{2}\right)$ with the interpretation that: (i) $\sigma^{i}\left(s_{1}^{i}\right)=$ invest if and only if $s_{1}^{i}>k_{1}$, (ii) $\sigma^{i}\left(s_{1}^{i}, s_{2}^{i}\right)=$ invest if and only if $s_{2}^{i}>k_{2}$ for all $i$. An equilibrium in symmetric switching strategies is a $k^{*}$ such that player $i$ 's strategy is a best response at every information set given (i) her beliefs about the state of the world, and given (ii) the equilibrium behavior of all other agents.

\section{Economic Interpretations}

The general payoff structure of our model nests a wide variety of more specific models. We provide three detailed examples below.

Fixed Horizon Technology Adoption Problem (FH). Suppose players can invest in a new technology with an unknown quality. This technology exhibits positive network effects and becomes obsolete in period $T+1$. For simplicity, players are only allowed to invest in period 1 or period 2 and have a common discount factor $\delta$. Call a player who invested at time one (two) an (a) early (late) adopter. When investing, players need to pay a setup cost $s \geq 0$. The (net of any per-period cost) return of the investment in period $t(t=1, \ldots, T)$, is given by $v_{t}^{i}=\tilde{\theta}+m_{t}$, where $m_{t}$ denotes the mass of players who invest in period $t$ or who have invested earlier. Assume, for the sake of simplicity, that $T=2$. In this case the payoff of a player investing in period 1 is given by

$$
V_{1}^{i}=(1+\delta) \tilde{\theta}+(1+\delta) n_{1}+\delta n_{2}-s
$$

and of a player investing in period 2 is given by

$$
V_{2}^{i}=\delta\left(\tilde{\theta}+n_{1}+n_{2}\right)-\delta s .
$$

Setting $\theta=\tilde{\theta}-\frac{s}{(1+\delta)}+1$ and using the following utility transformation $U_{t}^{i}=\frac{V_{t}^{i}}{(1+\delta)}$ shows that this economic model is a special case of our model in which $\alpha=\tau=$ 
$\frac{\delta}{1+\delta}<1, \gamma=1$, and $\Delta=\frac{\delta}{1+\delta} s .^{11}$

Note that at time one the early adopters do not enjoy any network benefits from the late adopters. Therefore early adopters care more about the mass of players who bought the technology at time one than about the mass of players who bought it at time two (which explains why in this case $\alpha<1$ ). The FH model can be interpreted as a stylized model of the credit card industry. The more popular a credit card becomes, the more widespread its acceptance will be. Early adopters of a credit card are therefore hampered by its small installed base in the sense that they will find few shops willing to accept it. On the other hand, late movers care as much about the mass of early as about the mass of late adopters (which explains why in this case $\gamma=1$ ). ${ }^{12}$ Whenever an early (late) adopter exhibits a stronger preference for her fellow adopters to invest early (late), we say that our model exhibits a cohort effect for the early (late) adopters.

Adopting a Technology with a Fixed Lifespan (FL). Rather than assuming that the technology becomes obsolete at time $T+1$, suppose the technology, once bought, can be used for $T$ periods. For the sake of simplicity, assume that $T=2$ (i.e. in this case an early adopter uses her technology at times one and two, while a late adopter uses it at times two and three). If the setup remains otherwise unchanged, one can use a similar procedure as above to show that this is a special case of our model in which $\tau=\delta, \alpha=\delta \gamma<\gamma=\frac{1}{1+\delta}<1$, and $\Delta=0 .{ }^{13}$

To illustrate this interpretation, consider the following example: Assume everyone has the opportunity to buy a video player. The more people who buy a video player, the higher the availability of video movies, video rental stores, etc. A video player can only be used for two periods. Everyone knows that at time 3 the DVD player will be introduced in our economy. As DVD technology is superior to video technology, from time 3 on, no one wants to buy a new video player anymore. However, people only switch to the superior DVD technology once their video

\footnotetext{
${ }^{11}$ If $T>2$, one should set $\theta=\tilde{\theta}-\frac{s}{1+\delta+\ldots+\delta^{T-1}}+1$ and use the following utility transformation: $U_{t}^{i}=\frac{V_{t}^{i}}{1+\delta+\ldots+\delta^{T-1}}$. After some computations we then get that $\alpha=\tau=\frac{\delta+\ldots+\delta^{T-1}}{1+\delta+\ldots+\delta^{T-1}}, \gamma=1$, and $\Delta=\frac{\delta^{T} s}{\left(\delta+\ldots+\delta^{T-1}\right)\left(1+\delta+\ldots+\delta^{T-1}\right)}$.

${ }^{12}$ In the credit card example, one may want to think about $T$ as tending towards infinity.

${ }^{13}$ If $T>2$ one must apply the utility transformation which appears in our earlier footnote. One can check that the values of $\tau, \alpha$ and $\Delta$ then remain unchanged. $\gamma$ would then be equal to $\frac{1+\delta+\ldots+\delta^{T-2}}{1+\delta+\ldots+\delta^{T-1}}$.
} 
player becomes "too old" (i.e. early adopters switch to the superior technology at time three, while late adopters switch to the new technology at time four). In this set-up for the same reason as the one explained in our earlier interpretation, our model exhibits a cohort effect for the early adopters. However, in this case late adopters know that the installed base will become smaller at time three due to the early adopters' switching to the new technology. Therefore, the FL model also exhibits a cohort effect for late adopters.

The model can be adopted to account for other environments. Consider, for example, a consumer deciding when to buy a given software. One can easily incorporate situations in which at time two a later version of a computer software is sold that is imperfectly compatible with the earlier version. The following example shows that one can also imagine situations in which cohort effects are absent.

Pledging to Invest (=PI). Suppose there are two periods in which players can commit to invest into a project prior to the time in which the project will take place. For example, firms may commit to buy some land in a soon-to-be developed industrial zone (or individuals may commit to become a member of some club or join a lobbying organization). In the first period, the land is sold at a lower price than in the second period (or there is a reduced membership rate). The more players invest in either period, the better the infrastructure provided (or the more exciting it will be to visit the club or the more influential will the lobbying organization be). In period 3, all players that committed to invest pay the amount due and start getting the benefit from the planned activity. This can be captured by a model in which $\alpha=\gamma=\tau=1$ and $\Delta>0$. This example is thus void of any cohort effects.

\section{Analysis of Strategic Waiting}

In this section we analyze the dynamic investment game. We first introduce some concepts that will be used throughout the following subsections. In the first subsection, we define dynamic strategic complementarity and show that it implies the existence of a unique rationalizable outcome of the dynamic investment game. We also show, however, that contemporaneous strategic complementarity does not necessarily imply dynamic strategic complementarity. The next subsection characterizes a class of symmetric switching equilibria. This allows us to do comparative statics for technology adoption problems for which the investment game has a 
unique equilibrium. We also use this characterization in the final subsection to illustrate multiplicity of equilibria in the absence of dynamic strategic complementarity. In essence, in the absence of dynamic strategic complementarity players have a strong incentive to invest when other players invest. This gives rise to a coordination problem of when to invests that allows for self-fullfilling expectations.

Let

$$
h\left(s_{2}^{i}, \sigma\right) \equiv s_{2}^{i}+E\left(\gamma n_{1}+n_{2} \mid s_{2}^{i}, \sigma\right)-1-\Delta .
$$

$h\left(s_{2}^{i}, \sigma\right)$ is the expected payoff of a player who invests in the second period after getting a signal $s_{2}^{i}$, expecting that all other players play according to the strategy profile $\sigma$. Similar, we define

$$
W\left(s_{1}^{i}, \sigma\right) \equiv \frac{\tau}{2} \max \left\{0, h\left(s_{1}^{i}+\epsilon, \sigma\right)\right\}+\frac{\tau}{2} \max \left\{0, h\left(s_{1}^{i}-\epsilon, \sigma\right)\right\} .
$$

$W\left(s_{1}^{i}, \sigma\right)$ denotes the gain of waiting for player $i$, given her first-period signal $s_{1}^{i}$ and given that all other players play according to $\sigma$. If player $i$ postpones her investment decision, then with probability $1 / 2$ she will get "bad news," i.e. she will learn that at time one she was too optimistic because $\epsilon_{1}^{i}=+\epsilon$. With probability $1 / 2$, however, she will receive "good news" in the sense that she will learn that $\epsilon_{1}^{i}=-\epsilon$. Equation (2) states that player $i$ 's gain of waiting equals her expected second-period payoff given that she will make an optimal second-period investment decision (i.e. not invest at time two if and only if her gain of investing is negative). For brevity, define

$$
g\left(s_{1}^{i}, \sigma\right) \equiv s_{1}^{i}+E\left(n_{1}+\alpha n_{2} \mid s_{i}^{1}, \sigma\right)-1-W\left(s_{i}^{1}, \sigma\right) .
$$

Trivially, it is optimal to invest in the first period for a player with a signal $s_{1}^{i}$ (who believes that all his rivals play according to $\sigma$ ) if and only if $g\left(s_{1}^{i}, \sigma\right) \geq 0$.

\subsection{Dynamic Strategic Complementarity and Uniqueness}

In this subsection, we first define dynamic strategic complementarity, which is a condition on ex-post payoffs. Intuitively, because we look for a condition on expost payoffs, we can ignore the dynamic aspect of the investment problem when defining strategic complementarity. From an ex-post perspective, a player either did not invest in either period (which we refer to as action 0), invested in the second period (which we refer to as action $a_{2}$ ), or invested in the first period (which we refer to as action $a_{1}$ ). Think of not investing as the lowest action and investing 
in the first period as the highest action. We say there is dynamic strategic complementarity whenever it is the case that if a positive mass of players moves to a higher action, the payoffs of moving to a higher action weakly increase.

Formally, denote the difference in ex-post payoffs between investing in the second period and not investing by

$$
\Delta U^{i}\left(a_{2}, 0\right) \equiv \tau\left(\theta+\gamma n_{1}+n_{2}-1-\Delta\right)
$$

and denote the difference between investing in the first period and investing in the second period by

$$
\Delta U^{i}\left(a_{1}, a_{2}\right) \equiv \theta+n_{1}+\alpha n_{2}-1-\tau\left(\theta+\gamma n_{1}+n_{2}-1-\Delta\right) .
$$

We say that the payoffs exhibit dynamic strategic complementarity if and only if:

$$
\begin{gathered}
(i) \frac{\partial \Delta U^{i}\left(a_{2}, 0\right)}{\partial n_{2}}=\tau \geq 0, \\
(i i) \frac{\partial \Delta U^{i}\left(a_{1}, a_{2}\right)}{\partial n_{2}}=\alpha-\tau \geq 0, \\
(i i i) \frac{\partial \Delta U^{i}\left(a_{2}, 0\right)}{\partial n_{1}}-\frac{\partial \Delta U^{i}\left(a_{2}, 0\right)}{\partial n_{2}}=\tau(\gamma-1) \geq 0, \\
\text { (iv) } \frac{\partial \Delta U^{i}\left(a_{1}, a_{2}\right)}{\partial n_{1}}-\frac{\partial \Delta U^{i}\left(a_{1}, a_{2}\right)}{\partial n_{2}}=1-\tau \gamma+\alpha-\tau \geq 0 .
\end{gathered}
$$

Condition (i) states that as more players invest in the second period, investing in the second period becomes more attractive relative to not investing. This condition is implied by the fact that the contemporaneous payoff function exhibits strategic complementarity. Condition (ii) requires that if more players invest in period 2, it becomes weakly more profitable to invest early. Intuitively, it implies that as more players invest in the second period, there is no additional gain from switching and investing late rather than early. It thus requires that the inter-period network effect $\alpha$, which measures the increase in payoffs for a player who invests immediately, is no less than the discount factor $\tau$, which measures the increase in payoffs for a player who invests late. Condition (iii) states that as more players move from investing late to investing early, it becomes weakly more profitable to invest late rather than not to invest at all. Observe that this condition can only be satisfied in the absence of late mover cohort effects, i.e. if $\gamma=1$. Finally, condition (iv) states that as more investors invest early rather than late, investing early becomes 
more profitable. This is a rather weak condition, which is satisfied if $\alpha \geq \tau$ and $\gamma=1$. We conclude that our payoffs exhibit dynamic strategic complementarity if and only if $\alpha \geq \tau$ and $\gamma=1$. This implies the following observation:

Proposition 1 The fixed horizon technology adoption problem (FH) and the pledging to invest model (PI) exhibit contemporaneous and dynamic strategic complementarity. The adopting a technology with a fixed lifespan problem (FL) exhibits contemporaneous but not dynamic strategic complementarity.

The above observation implies that with irreversible investments, contemporaneous network effects do not imply that the investment game satisfies dynamic strategic complementarity. Rather, whether the dynamic problem satisfies dynamic strategic complementarity depends on the exact nature of the technology adoption problem. The important consequences of whether the payoffs satisfy dynamic strategic complementarity or not, are discussed below. We start by observing that dynamic strategic complementarity implies the existence of a unique rationalizable outcome in our setup. ${ }^{14}$

Proposition 2 If there are positive waiting costs $(\tau<1$ or $\Delta>0)$ and overall strategic complementarities in payoffs $(\gamma=1$ and $\alpha \geq \tau)$, there exists an essentially unique rationalizable outcome.

Intuitively, the argument proceeds as follows. Suppose player $i$ did not invest at time one. Then, not investing (at time two) is dominated for her whenever $s_{2}^{i}>1+\Delta$. Now consider any type who has a signal $s_{1}^{i}>1+\Delta+\epsilon$. This player foresees that she would want to invest in the second period independent of whether she receives good news or bad news. But under the assumption that no other player invests, it is obvious that waiting and investing for certain is dominated by investing immediately and saving the waiting cost. Indeed, understanding that she will invest in the second period if $s_{2}^{i}>1+\Delta$, a player at time one can calculate her benefit of investing under the assumption that no other player invests in either period, and determine a cutoff level $\bar{s}_{1}^{1}$ such that for all higher first-period signals, she prefers to invest immediately. Dynamic strategic complementarity ensures that investing dominates not investing for all players who receive a signal $s_{1}^{i}>\bar{s}_{1}^{1}$ or

\footnotetext{
${ }^{14}$ In static global games, one typically derives the existence of a unique rationalizable equilibrium. In our dynamic game, we only show a unique rationalizable outcome because we cannot determine behavior at out-of-equilibrium information sets through the iterative elimination of dominated strategies.
} 
$s_{2}^{i}>1+\Delta$. The reason is that as other players invest (in either of the two periods), investing early becomes even more attractive relatively to investing late, which in turn becomes even more attractive relatively to not investing at all. Call $\bar{s}^{1}=\left(\bar{s}_{1}^{1}, 1+\Delta\right)$.

A rational player anticipates that all other players invest (in one of the two periods) if they receive a sufficiently high signal. Now, consider a player with a second-period signal slightly below $1+\Delta$ and suppose she has not invested in period one. Because a player with signal $1+\Delta$ expects at least half of the population to invest, a player with a signal close to $1+\Delta$ strictly prefers to invest. Similar, a player with a signal $s_{1}^{i}=\bar{s}_{1}^{i}$ must expect that half of the population invests early and perhaps that some players invest late. But as the number of early (and late) investors increases, dynamic strategic complementarity implies that waiting becomes less desirable. Hence, we can determine a new cutoff vector $\bar{s}^{2}=\left(\bar{s}_{1}^{2}, \bar{s}_{2}^{2}\right)$ where both $\bar{s}_{t}^{2}$,s are computed such that if $s_{t}^{i}=s_{t}^{2}$, player $i$ is indifferent between investing and not investing given that player $i$ anticipates that all players invest at time one (two) if their first-period signals are higher than $s_{1}^{1}$ (if they did not invest at time one and if their second-period signals are higher than $1+\Delta$ ). Repeating this procedure, we get a decreasing sequence of cutoff vectors. This sequence must converge, as investing is dominated for sufficiently low signals. Furthermore, it must converge to a symmetric switching equilibrium. To see this note that a player with a signal $\bar{s}_{1}^{\infty}$ must be indifferent between investing immediately and waiting presuming that her "rivals" invest if and only if they receive a signal above the cutoff vector $\left(\bar{s}_{1}^{\infty}, \bar{s}_{2}^{\infty}\right)$. The reason is that it must be optimal for players with higher signals to invest and it can not be strictly optimal for players with a slightly lower first-period signal to invest, by the construction of the sequence. Players with even lower first period signals prefer not to invest if their rivals play according to $\left(\bar{s}_{1}^{\infty}, \bar{s}_{2}^{\infty}\right)$ because they have a lower estimate of the fundamental and expect less players to invest, which makes waiting more desirable. A similar argument ensures that a player with a second-period signal $\bar{s}_{2}^{\infty}$ is indifferent between investing and not investing.

For players who receive sufficiently low signals it is a dominant strategy not to invest, even if they expect all other players to invest. Mirroring the above argument, one can construct an increasing sequence of cutoff vectors below which every player refrains from investing. This sequence must converge to a symmetric switching equilibrium. To complete the proof, we suppose that the iterative 
elimination from above and below converge to different symmetric switching equilibria and show that this leads to a contradiction. To see the logic underlying the contradiction, observe that a player who receives a signal equal to the first(respectively second-) period cutoff level is indifferent between investing and waiting (respectively not investing). Thus, a player who receives a cutoff signal must expect less investment activity in the higher equilibrium as he is more optimistic about the fundamental. For a player who receives a first- or second-period cutoff signal, the expectation of the total number of investors is function of the difference $k_{1}-k_{2}$ only because all realizations of the fundamental are equally likely. In the higher equilibrium, a player with a signal equal to the second-period cutoff level expects lower investment activity only if less players have already invested in the first period, that is $k_{1}$ is higher relative to $k_{2}$. This requires that the difference $k_{1}-k_{2}$ has a higher value in the higher equilibrium. But a player with a signal equal to the first-period cutoff level $k_{1}$ expects a lower level of investment activity only if $k_{2}$ is relatively higher, which ensures that he expects less players to invest in the second period. This requires that $k_{1}-k_{2}$ has a lower value in the higher equilibrium, which establishes the contradiction. Thus, there exists a unique symmetric switching equilibrium and hence a unique rationalizable outcome.

The above argument uses three ingredients. Firstly, players with sufficiently high signals want to invest and players with sufficiently low signals do not want to invest, independent of their expectations of what their rivals are doing. Secondly, due to waiting costs, a player with a sufficiently high signal prefers to invest immediately rather than to wait and invest late if he expects no one else to invest. Thirdly, dynamic strategic complementarity ensures that we can rank the investment decision from a lowest (not investing) to a highest decision (investing early). Using this ranking we can extend the standard contagion argument.

\subsection{Characterization of Symmetric Switching Equilibria}

In this section, we characterize some symmetric switching equilibria. This allows us to derive comparative statics results in the FH and the PI interpretation of our model. Furthermore, we will use the explicit characterization of equilibria to discuss how the absence of dynamic strategic complementarity can lead to multiple equilibria in the following subsection.

A necessary condition for a strategy profile $k^{*}$ in which $k_{t}^{*}<\infty($ for $t=1,2)$ to 
be an equilibrium (strategy profile) in symmetric switching strategies is that it satisfies the following two equations:

$$
\begin{aligned}
& g\left(k_{1}^{*}, k^{*}\right)=0, \\
& h\left(k_{2}^{*}, k^{*}\right)=0 .
\end{aligned}
$$

Equation (4), which can be rewritten as

$$
k_{1}^{*}+E\left(n \mid k^{*}, s_{i}^{1}=k_{1}^{*}\right)-1=W\left(k, s_{i}^{1}=k_{1}^{*}\right),
$$

states that a player possessing a first-period signal $s_{1}^{i}=k_{1}^{*}$ must be indifferent between investing and waiting. Equation (5) says that a player who receives a second-period signal $s_{2}^{i}=k_{2}^{*}$ is indifferent between investing and not investing. In case $k_{1}^{*}=\infty$, equation (4) must be replaced by the condition $g\left(s_{1}^{i}, k^{*}\right) \leq 0$, for all $s_{1}^{i}$. That is, it must be optimal to refrain from investing for all first period signals. Similar, in case $k_{2}^{*}=\infty$, condition (5) must be replaced by the condition $h\left(k_{2}^{*}, k^{*}\right) \leq 0$ for all $s_{2}^{i}$.

If $g\left(s_{1}^{i}, k\right)$ (respectively $h\left(s_{2}^{i}, k\right)$ ) are monotonically increasing in $s_{1}^{i}$ (respectively $s_{2}^{i}$ ), then any strategy profile $k^{*}$ satisfying (4) and (5) is clearly an equilibrium strategy profile. However, note that $h(\cdot)$ is a function of $E\left(\gamma n_{1}+n_{2} \mid \cdot\right)$. In some symmetric switching equilibria, players refrain from investing for sufficiently low signals and all players invest immediately in the first period for sufficiently high signals. For intermediate signals, however, players wait and invest in the second period when receiving good news. If there are late mover cohort effects $(\gamma<1)$ in such a candidate equilibrium, $h(\cdot)$ need not be monotone in $s_{2}^{i}$ as $E\left(n_{2} \mid \cdot\right)$ is not. When characterizing the set of symmetric switching equilibria, we first look for candidate equilibria that solve equations (4) and (5) and then carefully verify that these candidate equilibria are indeed equilibria. To economize on notation, we will from now on denote equilibrium strategy profiles (and candidate equilibria) by $k$ rather than $k^{*}$.

We refer to an equilibrium $k$ in which no player invests in the second period as an immediate investment equilibrium. Formally, $k$ is an immediate investment equilibrium if and only if $k_{2} \geq k_{1}+\epsilon$.

Proposition 3 There exists an immediate investment equilibrium if and only if $\Delta \geq-\frac{1}{2}+\epsilon+\frac{3}{4} \gamma$. In an immediate investment equilibrium $k_{1}=\frac{1}{2}$. 
The parameter condition under which an immediate investment equilibrium exists is intuitive. As the payoff reduction for late movers $\Delta$ increases, players have an incentive to move early and thus an immediate investment equilibrium is more likely to exist. As $\gamma$ decreases, a player who deviates in order to invest late enjoys a smaller (inter-period) network effect, which makes deviating less attractive. Hence, as $\gamma$ decreases, an immediate investment equilibrium is more likely to exists. To understand why an increase in $\epsilon$ makes it harder to sustain an immediate investment equilibrium, consider a player with a signal $s_{1}^{i}=1 / 2$. This player is uncertain about whether the fundamental $\theta$ is high enough to make his investment profitable. As $\epsilon$ increases, more uncertainty about $\theta$ is resolved between period one and two, which makes it more desirable to wait in order to receive more information.

To further understand the role of $\epsilon$, it is useful to note that the expected network benefit for a player with a signal $s_{1}^{i}=k_{1}$ is $1 / 2$ in an immediate investment equilibrium. ${ }^{15}$ Intuitively, player $i$ knows that all players possessing a signal higher (lower) than hers invest (do not invest) at time one. Player $i$ asks herself the question: What is the mass of players who received a first-period signal greater than $k_{1}$ ? Player $i$ knows that $\theta$ lies in a $2 \epsilon$ neighborhood of $s_{1}^{i}$. If $\theta>s_{1}^{i}$, she knows that more than $1 / 2$ of the population possesses a signal higher than hers. Conversely, if $\theta<s_{1}^{i}$, she knows that more than $1 / 2$ of the population posses a signal strictly lower than hers. Given hat $\theta \mid s_{1}^{i}$ is symmetrically distributed around $s_{1}^{i}$, player $i$ knows that the event $\theta>s_{1}^{i}$ is as likely to occur as the event $\theta<s_{1}^{i}$. Therefore $E\left(n_{1} \mid s_{1}^{i}=k_{1},\left(k_{1}, \infty\right)\right)=1 / 2$. Stated differently, player $i$ always believes to lie in the center of the world. She always expects half of the population to possess a signal strictly higher than hers, with the other half possessing a signal strictly lower than hers.

Now, for the sake of argument, suppose that there is no inter-period network effect for late movers $(\gamma=0)$ and that $\Delta=0$. Then an immediate investment equilibrium does not exist whenever $\epsilon>1 / 2$. The intuition for this result is as follows: In an immediate investment equilibrium a player with a signal $s_{1}^{i}=k_{1}$ is indifferent between investing and not investing, which is the action she will take if she

${ }^{15}$ Formally, using the $n_{1}(\theta, k)$ function derived in Appendix 2 and the fact that

$$
E\left(n_{1} \mid s_{1}^{i}=k_{1}, k\right)=\frac{1}{4 \epsilon} \int_{k_{1}-2 \epsilon}^{k_{1}+2 \epsilon} n_{1}(\theta, k) d \theta,
$$

it is easy to verify that $E\left(n_{1} \mid s_{1}^{i}=k_{1}, k\right)=\frac{1}{2}$. 
decides to wait. So her expected payoff must be zero. Furthermore, as discussed above, she expects half of the population to get a better signal than herself. So her expected gain from the network effect is $1 / 2$. But if $\epsilon>1 / 2$, this player could wait, forfeit the expected network effect and only invest if she learns that she was too pessimistic. In this case her expected payoff when getting good news changes by $\epsilon-1 / 2$, while her expected payoff when getting bad news remains zero. So if $\epsilon>1 / 2$ this is a profitable deviation and an immediate investment equilibrium cannot exist. In general, the more uncertainty about the fundamental is revealed before the second period, the more attractive it becomes to wait, and the less likely it is that an immediate investment equilibrium exists.

We will refer to an equilibrium in which players with high signals invest immediately and players with intermediate signals wait and invest later when receiving good news (but not when receiving bad news) as an informative waiting equilibrium. When solving for informative waiting equilibria, it is convenient to slightly relax the definition of symmetric switching equilibria and solve for all symmetric strategy profiles that can be characterized by a vector $\left(k_{1}, k_{2}\right)$ with the interpretation that (i) $\sigma^{i}\left(s_{1}^{i}\right)=$ invest if and only if $s_{1}^{i}>k_{1}$, and (ii) for all $s_{2}^{i}<k_{1}+\epsilon$, $\sigma\left(s_{1}^{i}, s_{2}^{i}\right)=$ invest if and only if $s_{2}^{i}>k_{2}$. We refer to such equilibria as weak symmetric switching equilibria. The difference to our earlier definition is that we only require switching behavior on the equilibrium path. In the out-of-equilibrium event that a player with signal $s_{1}^{i}>k_{1}$ did not invest and gets a signal $s_{2}^{i}>k_{1}+\epsilon$, we do not solve for this player's optimal behavior explicitly. ${ }^{16}$ Formally, an informative waiting equilibrium is a (weak symmetric switching) equilibrium in which $k_{1}-\epsilon<k_{2}<k_{1}+\epsilon$.

For brevity, let $x \equiv 4 \epsilon+\gamma$ and let

$$
\begin{gathered}
D \equiv-16 \Delta+16 \epsilon-8+12 \gamma+[(2-\alpha)-(2-\tau) x]^{2}, \\
\Delta^{a} \equiv \Delta^{b}+\frac{1}{16}[(2-\alpha)-(2-\tau) x]^{2}, \\
\Delta^{b} \equiv-\frac{1}{2}+\frac{3}{4} \gamma+\epsilon,
\end{gathered}
$$

\footnotetext{
${ }^{16} \mathrm{We}$, nevertheless, require that player $i$ 's strategy is sequentially rational, i.e. that she invests in the second period if and only if it is profitable. This optimal behavior may, however, require a player with signal $s_{2}^{i}>k_{2}$ not to invest following an out-of equilibrium history in which she did not invest when receiving a signal $s_{1}^{i}>k_{1}$.
} 


$$
\Delta^{c} \equiv \frac{\gamma}{4}(1+\tau)-\frac{(1+\alpha)+4 \epsilon(1-\tau)}{4} .
$$

We are ready to characterize when an informative waiting equilibrium exists.

Proposition 4 There exists an informative waiting equilibrium $\left(k_{11}, k_{21}\right)$ if the following three conditions are satisfied: (a) $\Delta \leq \Delta^{a}$, (b) either $(2-\alpha)>(2-\tau) x$ or $\Delta \leq \Delta^{b}$, and (c) $\Delta>\Delta^{c}$. In this informative waiting equilibrium

$$
\begin{gathered}
k_{11}=\frac{1}{8}\left\{\tau(\tau-2) x^{2}+2 x[1-(1-\alpha)(1-\tau)]+(1-\alpha)^{2}+3+(x \tau-\alpha) \sqrt{D}\right\}, \\
k_{21}=\frac{1}{8}\left\{-\sqrt{D}(\alpha+8 \epsilon-x \tau)+x^{2} \tau^{2}+2 \tau x(1-\alpha-4 \epsilon-x)+(2-\alpha)^{2}-8(1-\alpha) \epsilon+2 \alpha(1+x)+16 \epsilon x\right\} .
\end{gathered}
$$

Furthermore, there exists an informative waiting equilibrium $\left(k_{12}, k_{22}\right)$ if the following three conditions are satisfied: (a) $\Delta \leq \Delta^{a}$, (d) $(2-\alpha)>(2-\tau) x$, and (e) $\Delta>\Delta^{b}$. In this informative waiting equilibrium

$$
\begin{gathered}
k_{12}=\frac{1}{8}\left\{\tau(\tau-2) x^{2}+2 x[1-(1-\alpha)(1-\tau)]+(1-\alpha)^{2}+3-(x \tau-\alpha) \sqrt{D}\right\}, \\
k_{22}=\frac{1}{8}\left\{\sqrt{D}(\alpha+8 \epsilon-x \tau)+x^{2} \tau^{2}+2 \tau x(1-\alpha-4 \epsilon-x)+(2-\alpha)^{2}-8(1-\alpha) \epsilon+2 \alpha(1+x)+16 \epsilon x\right\} .
\end{gathered}
$$

Conversely, there exists no other informative waiting equilibrium.

To understand under what conditions an informative investment equilibrium exists, suppose first that $(2-\alpha)<(2-\tau) x$, as is the case if the payoffs satisfy dynamic strategic complementarity. Then, since condition (d) is violated, the $\left(k_{12}, k_{22}\right)$ equilibrium does not exist. Next, observe that in this case conditions (a) and (b) are satisfied whenever $\Delta$ is too low to sustain an immediate investment equilibrium, i.e. when waiting to act on more information is profitable. The role of condition (c) is to ensure that the relevant decision for a player with signal $s_{1}^{i}=k_{1}$ is whether to wait for good news or whether to invest immediately. If it is violated, the player would prefer to invest in the second period also when getting bad news (which explains why condition (c) gives a lower bound on $\Delta$ ). Condition (c) can only be binding if the payoffs violate dynamic strategic complementarity. Whenever the payoffs satisfy dynamic strategic complementarity, the only reason to wait is to collect information in order to make a better informed decision. So if a player would prefer to invest when getting bad news, he could invest immediately and save the waiting costs. If cohort effects are such that dynamic strategic complementarity is violated, however, one may want to wait and invest both when 
getting good news and when getting bad news. In this case a player waits in order to benefit from a higher network effect. Note that this requires that $\gamma$ is sufficiently greater than $\alpha$; that is late movers must enjoy a higher inter-period network effect than early movers. The intuition for this is that a player with signal $s_{1}^{i}=k_{1}$ expects half of the population to invest in the first period. So she can expect at most half of the population to invest late. Therefore, she can only expect to gain a larger network effect by moving late if the inter-period network effect for late movers $\gamma$ is greater than its first period counterpart $\alpha$.

We are left to consider the case in which $(2-\alpha)>(2-\tau) x$. Trivially, this implies that conditions (b) and (d) are satisfied. Clearly, then the equilibrium $\left(k_{11}, k_{21}\right)$ exists for all $\Delta \in\left(\Delta^{c}, \Delta^{a}\right]$ and the equilibrium $\left(k_{21}, k_{22}\right)$ exists for all $\Delta$ in the nonempty interval $\left(\Delta^{b}, \Delta^{a}\right]$. Since an immediate investment equilibrium exists for all $\Delta>\Delta^{b}$, this implies that if $(2-\alpha)>(2-\tau) x$, there exist values of $\Delta$ for which our model has multiple equilibria as long as $\Delta^{a} \geq 0$. Observe that a necessary (though not sufficient) condition for $(2-\alpha)>(2-\tau) x$ is that the payoffs violate our definition of dynamic strategic complementarity. As either cohort effects increase (i.e. $\alpha$ or $\gamma$ decrease), the condition is more likely to be satisfied. One interpretation of this fact is that as cohort effects become more important, dynamic coordination becomes more important. A player then only wants to invest if she believes that the other players invest at the same point in time. Second, if $\tau<1$, then decreasing $\gamma$ is more likely to make this condition hold then decreasing $\alpha$ by the same amount, reflecting the fact that a first-period decision maker discounts the second-period investment payoffs. Third, as the uncertainty $\epsilon$ increases, the conditions is less likely to hold. Intuitively, as $\epsilon$ increases more uncertainty about the fundamental is revealed before the second period. For a player who is unsure whether he should invest in the first period, it is thus more profitable to wait for additional news and relatively less important to invest when the other players invest. As the coordination aspect becomes relatively less important, multiple equilibria are less likely to exists.

The following Lemma rules out the existence of other (weak) symmetric switching equilibria in all of the economic environments discussed in Section 3.

LEMMA 1 If $\tau<1$ or if $\alpha=\gamma=\tau=1$ and $\Delta>0$, then there exists no (weak) symmetric switching equilibrium in which $k_{1}=\infty$. Furthermore, if $\frac{1}{2}(\tau \gamma-\alpha)-$ $\epsilon(1-\tau)<\Delta$ then there exists no equilibrium in the class of (weak) symmetric switching equilibria in which $k_{2}<k_{1}-\epsilon<\infty$. 
The first set of conditions rule out an equilibrium in which players only invest in the second period. If $\tau<1$ players discount the payoffs of investing in the second period as their benefits from investing are delayed. In this case, as the fundamental $\theta$ increases without bound, the foregone first-period benefit grows without bound. In other words, if $\tau<1$, then it is a dominant strategy to invest in the first period for sufficiently high signals. Thus, there cannot exist an equilibrium in which players only invest in the second period. In the PI case considered, a player with a very high second period signal has a strict incentive to invest. Hence, a player with a very high first period signal realizes that she will want to invest in the second-period independent of whether she gets good or bad news. But then she is better of investing immediately and saving the waiting cost $\Delta$.

The second condition ensures that a symmetric switching equilibrium in which players wait in order to invest in the second period with certainty fails to exist. This type of behavior rules out any informational reason for waiting. Rather waiting must be driven by the desire to coordinate the timing of the investment. This can only be profitable if there are cohort effects and if, as discussed above, the second-period cohort effect is sufficiently less than the first-period cohort effect (i.e. $\gamma>\alpha$ ).

\subsection{Cohort Effects and Multiplicity}

In this subsection, we provide illustrative examples to discuss why the lack of dynamic strategic complementarity can lead to multiple equilibria. These examples help in distinguishing the underlying force behind our multiple equilibrium phenomena from that found in other dynamic global game models. We then observe, however, that even though the FL interpretation of our model always violates dynamic strategic complementarity, it has a unique equilibrium within the class of symmetric switching strategies for a wide range of parameter values.

Example 1. Consider the FL game with a discount factor of $\delta=3 / 5$ and let $\epsilon=1 / 64$. Using the normalization introduced in Section 3, one has $\tau=3 / 5$, $\alpha=3 / 8, \gamma=5 / 8$ and $\Delta=0$. Since $\Delta>\Delta^{b}=-1 / 64$ in this case, Proposition 3 implies that there exists an immediate investment equilibrium. Furthermore, as in addition $\Delta<\Delta^{a} \approx 0.046$ and $(2-\alpha)>(2-\tau) x$, Proposition 4 implies that there exists two informative waiting equilibria in this example. 
Indeed, in the above example there exist multiple continuation equilibria for some first-period cutoff levels. To see this, consider the second-period continuation game of the immediate investment equilibrium. That is suppose that it is common knowledge that all player invested in the first-period if and only if they received a signal $s_{1}^{i}>1 / 2$. Obviously, there exists a continuation equilibrium in which no player invests as otherwise the immediate investment equilibrium would not exist. We now show that there exists another continuation equilibrium in which an active player invests if and only if he receives a signal $s_{2}^{i}>1 / 2$. Consider first a player whose $s_{2}^{i}=\frac{1}{2}$. Using Lemma 3 (which can be found in the Appendix) it is easy to verify that $E_{2}\left(n_{1} \mid 1 / 2,(1 / 2,1 / 2)\right)=1 / 2$ and that $E_{2}\left(n_{2} \mid 1 / 2,(1 / 2,1 / 2)\right)=3 / 16$. Player $i$ 's gain of investing, given her anticipation that all active players with a $s_{2}^{i} \in\left[\frac{1}{2}, \frac{1}{2}+\epsilon\right]$ invest at time two, equals

$$
h\left(\frac{1}{2},\left(\frac{1}{2}, \frac{1}{2}\right)\right)=\frac{1}{2}+\frac{5}{8} \frac{1}{2}+\frac{3}{16}-1=0 .
$$

We next show that $\frac{\partial h\left(s_{2}^{i},\left(\frac{1}{2}, \frac{1}{2}\right)\right)}{\partial s_{2}^{i}}>0$ for all $s_{2}^{i} \in[1 / 2,1 / 2+\epsilon]$, thereby proving that it is optimal to invest for all signals above $1 / 2$ in the continuation game if all other players follow the same cutoff strategy. One has

$$
\begin{gathered}
\frac{\partial h\left(s_{2}^{i},\left(\frac{1}{2}, \frac{1}{2}\right)\right)}{\partial s_{2}^{i}}=1+\frac{\gamma}{2 \epsilon}\left[n_{1}\left(s_{2}^{i}+\epsilon,\left(\frac{1}{2}, \frac{1}{2}\right)\right)-n_{1}\left(s_{2}^{i}-\epsilon,\left(\frac{1}{2}, \frac{1}{2}\right)\right)\right] \\
+\frac{1}{2 \epsilon}\left[n_{2}\left(s_{2}^{i}+\epsilon,\left(\frac{1}{2}, \frac{1}{2}\right)\right)-n_{2}\left(s_{2}^{i}-\epsilon,\left(\frac{1}{2}, \frac{1}{2}\right)\right)\right]
\end{gathered}
$$

Using Lemma 3 to substitute all relevant $n_{1}(\cdot)$ 's and $n_{2}(\cdot)$ 's in the above equation, the reader can check that

$$
\frac{\partial h\left(s_{2}^{i},\left(\frac{1}{2}, \frac{1}{2}\right)\right)}{\partial s_{2}^{i}} \geq 1+\frac{2 \gamma-1}{8 \epsilon}>0 \quad \forall s_{2}^{i} \in[1 / 2,1 / 2+\epsilon] .
$$

Hence, there also exists a continuation equilibrium in which all active players with a $s_{2}^{i} \in[1 / 2,1 / 2+\epsilon]$ invest at time two.

Thus, in Example 1 the continuation game is not a global game. This bears some resemblance with the models of Angeletos, Pavan and Hellwig (2003) and Chamley (1999). Nevertheless, the multiplicity is driven by another force. In the papers mentioned above, all players observe a public signal, which informs them about the state of the world. For example in Angeletos, Pavan and Hellwig player observe that a devaluation has not occurred. From this, they can deduce in equilibrium 
that devaluing is never a dominant strategy for the central bank. Hence, attacking is never a dominant strategy in the continuation game. In Chamley, players draw inference about the state of the world based on the outcome induced by past aggregate behavior and their private signal. As the observation of past behavior is shared by all agents, it again acts similar to a public signal. In particular, if the observation becomes too informative about the state of the world, then Chamley's model has multiple equilibria. ${ }^{17}$ Because aggregate past behavior is not observed in our model, the above does not drive the multiplicity result in our model. Indeed, if investment was perfectly reversible as in Angeletos, Pavan and Hellwig, our model would predict a unique rationalizable outcome. ${ }^{18}$ Similar, if there was no endogenous timing decision, as in Chamley, our model would predict a unique rationalizable outcome.

The multiplicity in our model comes from the fact that with irreversible investment and strong cohort effects, players have an incentive to invest when other players invest. This gives rise to coordination problem regarding the timing of investment. Example 2 further illustrates this timing problem.

Example 2. $\gamma=1 ; \alpha=\frac{1}{2} ; \epsilon=\frac{1}{16} ; \tau=0.99$ and $\Delta=0.315$.

In this example

$\Delta^{b}=\frac{1}{4}+\frac{1}{16}=0.3125<\Delta=0.315<\Delta^{a}=\Delta^{b}+\frac{1}{16}((2-\alpha)-(2-\tau) x)^{2}=0.316$, and

$$
(2-\alpha)-(2-\tau) x \simeq 0.24>0 .
$$

Hence, from Propositions 3 and 4 we know that our example is characterized by multiple equilibria.

As $\gamma=1$, if players follow a cutoff strategy in the first period, then in Example 2 the continuation game is always a well defined global game. More precisely, fix any $k_{1}$ and construct an induced game in which nature invests on behalf of a player

\footnotetext{
${ }^{17}$ See the discussion in the Introduction.

${ }^{18}$ To continue to abstract from social learning, one would need to assume that the first-period investment payoffs are only observed after the second-period investment decision.
} 
in the first period if and only if the player receives a signal $s_{1}^{i}>k_{1}$ and which is otherwise identical to the above example. We now argue that this induced game is always solvable through iterative elimination of dominated strategy. Clearly it is not optimal to invest for very low signals. Iteratively eliminating strategies from below, there will be a unique level $\underline{s}_{2}^{\infty}$ below which it is optimal to refrain from investing. In case $\underline{s}_{2}^{\infty} \geq k_{1}+\epsilon$, iterative elimination of dominated strategies implies that no player wants to invest in the second period. Hence, consider the case in which $\underline{s}_{2}^{\infty}<k_{1}+\epsilon$. In this case, a player who receives a signal $s_{2}^{i}=\underline{s}_{2}^{\infty}$ is indifferent between investing and not investing if she presumes that all active players with a higher second-period signal invest. Because, however, $\gamma=1$ the profitability of investing late depends only on the state of the world and the total number of investors in either period. Now consider a player who receives a higher second-period signal and believes that all active player with a higher signal than herself invest. This player thus is more optimistic about the state of the world and must expect (weakly) more players to invest overall. But then she strictly prefers investing. In particular, for a player with signal $s_{2}^{i}=k_{1}+\epsilon$, the condition that all active players with a higher signal than herself invest is vacuous and therefore she strictly prefers investing. Iterative eliminating strategies from above, hence implies that all players with a signal above $s_{2}^{i}=\underline{s}_{2}^{\infty}$ have a strict incentive to invest.

Why then does Example 2 have multiple equilibria? The reason is that as $\alpha<\tau$ dynamic strategic complementarity is violated and a player who believes that more players wait and invest late, has a higher incentive to also wait and invest late. On the other hand, if she thinks that the other investors are more likely to move early, moving early becomes more attractive. Hence, the lack of dynamic strategic complementarity gives rise to a coordination problem regarding the timing of investment.

The lack of dynamic strategic complementarity, however, does not imply that the coordination problem regarding the timing of investment is severe enough to give rise to multiple equilibria. For example, if $\Delta$ is very high then investing early always dominates investing late and our game has a unique equilibrium. More interestingly, the following proposition gives necessary and sufficient conditions for the existence of a unique symmetric switching strategy equilibrium in the FL interpretation of our model. The proof follows immediately from the results of the previous subsection and is thus omitted.

Proposition 5 Consider the adopting a technology with a fixed lifespan (FL) 
interpretation of our model. In this interpretation, there exists multiple equilibria if and only if the following holds:

$$
\begin{gathered}
-\frac{1}{2}+\epsilon+\frac{3}{4} \gamma<0<-\frac{1}{2}+\epsilon+\frac{3}{4} \gamma+\frac{1}{16}[(2-\delta \gamma)-(2-\delta)(\gamma+4 \epsilon)]^{2} \\
(2-\delta \gamma)>(2-\delta)(\gamma+4 \epsilon) .
\end{gathered}
$$

One implication of the above proposition is that for any given level of setup costs $s$ and any given discount factor $\delta$, if the technology last a sufficiently large number of periods $T$, then the FL model has a unique symmetric switching equilibrium. The technical reason is that as $T$ increases, $\gamma$ approaches 1 and both $0<-\frac{1}{2}+\epsilon+\frac{3}{4} \gamma$ and $(2-\delta \gamma)<(2-\delta)(\gamma+4 \epsilon)$. Economically, the late mover cohort effect becomes less and less important and thus the dynamic coordination issue becomes less relevant. Hence even though dynamic strategic complementarity is only satisfied in the limit as $T \rightarrow \infty$, there exists a unique equilibrium within the class of symmetric switching strategies for all large enough $T$.

Similar, if players discount the future heavily, i.e. $\delta$ is very low, then $\gamma$ becomes large and there exists a unique symmetric switching strategy. Intuitively, as $\delta$ goes to zero players strongly discount the future and hence the belief that many investors move late does not suffice to encourage a player to wait and invest late. Again the dynamic coordination aspect becomes too small to sustain multiple equilibria. Furthermore, as $\epsilon$, which measures the uncertainty about the fundamental that is resolved between the first and the second period, becomes sufficiently large there exists a unique equilibrium. Intuitively, the belief that many investors invest early will have less of an impact because it is more important to wait and gather information about the true fundamental. In this sense, the dynamic coordination aspect becomes relatively less important and a unique symmetric switching equilibrium is more likely to exist.

\section{Comparative Statics}

In this section we restrict ourselves to the case in which our payoffs comply to our definition of dynamic strategic complementarities. We use the closed form solutions (computed in subsection 4.2) of our essentially unique equilibrium to establish some comparative static results. 
We start with the following technical clarification. If one takes the improper prior literally, then the probability that $\theta$ lies in any finite interval is zero and hence with probability one players have a dominant strategy. Nothing in our analysis hinges on the fact that the prior is distributed over the entire real line and one could assume instead that it is distributed $U[-a, a]$ for sufficiently large $a$, which we will do implicitly when deriving our comparative static results. More seriously, we will derive comparative static results on parameters of the underlying economic interpretations given in Section 3. When doing these comparative statics, we fix the distribution of $\tilde{\theta}$ and ask how investment activity is affected by changes of the underlying parameters. It is thus important to realize that as we change these parameters, not only do the equilibrium cutoff levels change but also for any realization of the true fundamentals $\tilde{\theta}$, the normalized realization of the fundamental $\theta$ changes.

We first show that as $\Delta$ increase more players invest immediately. Recall that in the PI interpretation, $\Delta$ reflects the discount in investing costs for players who invest early. As this discount increases, more player invest immediately. More generally, the result shows that subsidies for early adopters increase the speed with which the technology is adopted.

Proposition 6 Suppose there are positive waiting costs and dynamic strategic complementarity in payoffs. Then first period investment activity strictly increases in $\Delta$ over $\left[0, \Delta^{b}\right]$ and remains constant thereafter. Second period investment activity strictly falls in $\Delta$ over $\left[0, \Delta^{b}\right]$ and remains zero thereafter.

Next, we focus on the FH interpretation of our model. We first show that as the setup costs $s$ increases, investment activity falls in both periods. We then show that as the discount factor $\delta$ increases, there exists parameter values for which more players invest immediately and less players invest late. This is perhaps somewhat surprising because as $\delta$ rises, the ex-post difference between investing early and investing late $\Delta U\left(a_{1}, a_{2}\right)$ falls.

Proposition 7 Consider the fixed horizon technology adoption problem (FH). As the setup costs s increase, investment activity in both periods falls. As players become more patient, there exists parameter values for which early investment activity rises and late investment activity falls. 


\section{Conclusion}

We investigated irreversible investment decision with positive network effects using a dynamic global game approach. In contrast to most papers on global games, we did not focus on determining conditions on the prior distribution and signaling distribution that give rise to a unique equilibrium. Instead, we used a Laplacian prior, a simple signaling technology, and abstracted from social learning. This allowed us to focus on the interaction between positive network effects and irreversible investments. We showed that with irreversible investments positive contemporaneous network effects do not necessarily imply dynamic strategic complementarity.

Using this fact, we illustrated that in a dynamic setting the global game approach may not give rise to a unique prediction. If dynamic strategic complementarity is violated a dynamic coordination aspect arises: Players have an incentive to invest at the same time others do. If this dynamic coordination aspect is strong enough, our global game has multiple equilibria. Nevertheless, we found the global game approach to be powerful. Even in the fixed lifespan technology adoption problem (FL) that always failed dynamic strategic complementarity, we could provide weaker conditions for the existence of a unique symmetric switching strategy equilibrium. Indeed, we could show that there are at most three such equilibria in the FL problem.

Our results highlight that the assumption that the network benefit depends only on the total number of investors and not on when others invest can have strong consequences if investments are irreversible. Even in the financial sector, reversing ones investment decisions is typically costly. We believe an interesting question for future research is how big the impact of such transaction costs are in dynamic models of speculative attacks or other macroeconomic coordination failures. In our model cohort effects rest a.o. on technological factors (e.g. in the FL interpretation of our model it was assumed that early adopters use the technology during periods 1 and 2, while late adopters use the technology during periods 2 and 3). We believe that cohort effects may also arise in other contexts due to different reasons: For instance a successful speculative attack is more likely to occur when all speculators attack the currency at the same time than if they were to attack the peg at different moments in time. Future research may also shed some light on the nature and causes of cohort effects in different economic environments. 


\section{Appendix}

We start by establishing a few Lemmas and by introducing some notations.

LEMma $2 E\left(n_{j} \mid s_{1}^{i}, k\right)=\frac{1}{2} E\left(n_{j} \mid s_{2}^{i}=s_{1}^{i}+\epsilon, k\right)+\frac{1}{2} E\left(n_{j} \mid s_{2}^{i}=s_{1}^{i}-\epsilon, k\right) \forall j=1,2$.

Proof: Trivially, one has

$$
\begin{gathered}
E\left(n_{j} \mid s_{1}^{i}, k\right)=\frac{1}{4 \epsilon} \int_{s_{1}^{i}-2 \epsilon}^{s_{1}^{i}+2 \epsilon} n_{j}(\theta, k) d \theta \\
=\frac{1}{2}\left\{\frac{1}{2 \epsilon} \int_{s_{1}^{i}-2 \epsilon}^{s_{1}^{i}} n_{j}(\theta, k) d \theta+\frac{1}{2 \epsilon} \int_{s_{1}^{i}}^{s_{1}^{i}+2 \epsilon} n_{j}(\theta, k) d \theta\right\} \\
=\frac{1}{2} E\left(n_{j} \mid s_{2}^{i}=s_{1}^{i}+\epsilon, k\right)+\frac{1}{2} E\left(n_{j} \mid s_{2}^{i}=s_{1}^{i}-\epsilon, k\right) .
\end{gathered}
$$

Q.E.D.

LEMma 3 One has

$$
n_{1}(\theta, k)= \begin{cases}0 & \text { if } \theta<k_{1}-2 \epsilon, \\ \frac{2 \epsilon+\theta-k_{1}}{4 \epsilon} & \text { if } k_{1}-2 \epsilon \leq \theta<k_{1}+2 \epsilon, \\ 1 & \text { if } k_{1}+2 \epsilon \leq \theta,\end{cases}
$$

and $\forall k_{2} \in\left(k_{1}-\epsilon, k_{1}+\epsilon\right)$, one has

$$
n_{2}(\theta, k)= \begin{cases}0 & \text { if } \theta<k_{2}-\epsilon, \\ \frac{\epsilon-k_{2}+\theta}{4 \epsilon} & \text { if } k_{2}-\epsilon \leq \theta<k_{1}, \\ \frac{k_{1}+\epsilon-k_{2}}{4 \epsilon} & \text { if } k_{1} \leq \theta<k_{2}+\epsilon, \\ \frac{k_{1}+2 \epsilon-\theta}{4 \epsilon} & \text { if } k_{2}+\epsilon \leq \theta<k_{1}+2 \epsilon, \\ 0 & \text { if } k_{1}+2 \epsilon \leq \theta .\end{cases}
$$


Proof: To compute $n_{1}(\cdot)$ and $n_{2}(\cdot)$ we will work with the following figure and variants thereof:

\section{[Insert Figure 1 here]}

In the above figure,the two thick black lines represent all the possible realizations that $\left(\epsilon_{2}^{i}, \epsilon_{1}^{i}\right)$ can take. For example, player $a$ in the graph received a $\epsilon_{1}^{i}=\epsilon_{2}^{i}=-\epsilon$, while player $d$ received $\epsilon_{1}^{i}=\epsilon_{2}^{i}=\epsilon$. All the players who received a $\epsilon_{1}^{i}=-\epsilon$ are situated on the lower thick line. Those players will receive good news at time two. Similarly, all players situated on the upper thick line will receive bad news at time two. Actually, one can best think of the graph above as possessing a third dimension representing $f\left(\left(s_{1}^{i}, s_{2}^{i}\right) \mid \theta\right)$. From above, we know that $\operatorname{Pr}\left(\epsilon_{1}^{i}=\epsilon\right)=\frac{1}{2}$, that $\epsilon_{2}^{i}$ is independent of $\epsilon_{1}^{i}$ and that $\epsilon_{2}^{i}$ is drawn from a uniform distribution. Hence, we know that half of our population receive an $\epsilon_{1}^{i}=-\epsilon$ and lie, uniformly distributed, on the lower thick black line, while the other half lie, uniformly distributed, on the upper thick black line. Therefore, this third dimension is "trivial" and is not shown in the figure.

The diagonal " $k_{1}-\theta$ " represents the combination of all $\left(\epsilon_{2}^{i}, \epsilon_{1}^{i}\right)$ such that $\epsilon_{1}^{i}+\epsilon_{2}^{i}=$ $k_{1}-\theta$. All players who lie to its right and above possess a first-period signal $s_{1}^{i}>k_{1}$, since $s_{1}^{i}=\theta+\epsilon_{1}^{i}+\epsilon_{2}^{i} \geq k_{1}$ if and only if $\epsilon_{1}^{i}+\epsilon_{2}^{i} \geq k_{1}-\theta$. Hence, the diagonal $k_{1}-\theta$ permits us to compute the mass of period one investors.

$e$ denotes the point in which the diagonal $k_{1}-\theta$ cuts the upper thick black line. What are the coordinates of point $e$ ? We know that all points on the diagonal satisfy the restriction that their $x$ and $y$ coordinates sum up to $k_{1}-\theta$. We also know that in point $e$ the $y$ coordinate equals $+\epsilon$. Therefore the coordinates of point $e$ are $\left(k_{1}-\theta-\epsilon, \epsilon\right)$. If $k_{1}=\theta$, then the diagonal goes through the points $b$ and $c$ (in both points $k_{1}-\theta=\theta-\theta=0=\epsilon-\epsilon$ ). If $k_{1}=\theta-2 \epsilon$, then the diagonal goes through the point $a$. This is because in the point $a, k_{1}-\theta=-2 \epsilon$. Similarly, if $k_{1}=\theta+2 \epsilon$, then the diagonal goes through the point $d$. By continuity, if $\theta-2 \epsilon<k_{1}<\theta$, the diagonal $k_{1}-\theta$ cuts the thick line situated on the $\mathrm{X}$-axis. Similarly, if $\theta<k_{1}<\theta+2 \epsilon$, the diagonal cuts the upper thick line.

The vertical " $k_{2}-\theta$ " permits us to compute the mass of players who invest at time two. For example, in graph one all players situated on the $\mathrm{X}$-axis and to the right of $k_{2}-\theta$ invest at time two. The reason is that an active player having received 
an $\epsilon_{1}^{i}=-\epsilon$ invests at time two if and only if $s_{2}^{i}=\theta+\epsilon_{2}^{i}>k_{2}$ or if and only if $\epsilon_{2}^{i}>k_{2}-\theta$. $f$ denotes the point in which the vertical $k_{2}-\theta$ cuts the $\mathrm{X}$-axis.

When doesn't the vertical $k_{2}-\theta$ cross the lower thick line? $k_{2}-\theta>\epsilon$ if and only if $k_{2}-\epsilon>\theta$. This is intuitive: If $\theta$ is "low", then no player who received good news will invest at time two. In that case point $f$ lies to the right of point $b$. Similarly, $k_{2}-\theta<-\epsilon$ if and only if $k_{2}+\epsilon<\theta$. In hat case point $f$ lies to the left of point $a$.

When computing $n_{2}(\cdot)$, we focus on an equilibrium in which $k_{1}-\epsilon<k_{2}<k_{1}+\epsilon$. This implies that

$$
k_{1}-2 \epsilon<k_{2}-\epsilon<k_{1}<k_{2}+\epsilon<k_{1}+2 \epsilon \text {. }
$$

Therefore we must consider the following six cases: (i) $\theta<k_{1}-2 \epsilon$, (ii) $k_{1}-2 \epsilon<$ $\theta<k_{2}-\epsilon$, (iii) $k_{2}-\epsilon<\theta<k_{1}$, (iv) $k_{1}<\theta<k_{2}+\epsilon$, (v) $k_{2}+\epsilon<\theta<k_{1}+2 \epsilon$, and (vi) $k_{1}+2 \epsilon<\theta$.

In case (i) we know that $\theta<k_{1}-2 \epsilon<k_{2}-\epsilon$. From above, we know that this implies that points $e$ and $f$ lie to the right of (respectively) $d$ and $b$. Hence, $n_{1}\left(\theta<k_{1}-2 \epsilon, k\right)=n_{2}\left(\theta<k_{1}-2 \epsilon, k\right)=0$.

In case (ii) we know that point $f$ lies to the right of point $b$, implying that - due to a low $\theta-n_{2}\left(k_{1} 2 \epsilon<\theta<k_{2} \epsilon, k\right)=0$. Moreover we also know that in this case $\theta<k_{1}$ which implies that the diagonal $k_{1}-\theta$ cuts the upper thick line. This case is represented in Figure 2.

\section{[Insert Figure 2 here]}

In this case all players situated between points $e$ and $d$ invest at time one. Hence, it is straightforward to compute that $n_{1}\left(k_{1}-2 \epsilon<\theta<k_{2}-\epsilon, k\right)=\frac{2 \epsilon+\theta-k_{1}}{4 \epsilon}$.

In case (iii) $\theta$ is still strictly lower than $k_{1}$ but the vertical $k_{2}-\theta$ crosses the two thick black lines. This case is represented in Figure 1. The coordinates of $e$ are $\left(k_{1}-\theta-\epsilon, \epsilon\right)$ and the ones of point $f^{\prime}$ are $\left(k_{2}-\theta, \epsilon\right)$. We are focusing on an equilibrium in which $k_{2}>k_{1}-\epsilon$. This last inequality can be rewritten as $k_{2}-\theta>k_{1}-\theta-\epsilon$ which amounts to stating that point $f^{\prime}$ always lies to the right of point $e$. From above we thus know that $n_{1}\left(k_{2}-\epsilon<\theta<k_{1}, k\right)=\frac{2 \epsilon+\theta-k_{1}}{4 \epsilon}$. All players lying between $[f, b]$ invest at time two. Hence, $n_{2}\left(k_{2}-\epsilon<\theta<k_{1}, k\right)=\frac{\epsilon-k_{2}+\theta}{4 \epsilon}$. 
In case (iv), $\theta$ is higher than $k_{1}$. This implies that the diagonal $k_{1}-\theta$ cuts the lower thick line. Therefore all players who received an $\epsilon_{1}^{i}=\epsilon$ (and who are thus situated on the upper thick line) invest at time one. This case is represented in Figure 3.

\section{[Insert Figure 3 here]}

From above we know that the coordinates of point $e$ are $\left(k_{1}-\theta+\epsilon,-\epsilon\right)$. The coordinates of point $f$ are $\left(k_{2}-\theta,-\epsilon\right)$. Note that $k_{2}-\theta<k_{1}-\theta+\epsilon$ if and only if $k_{2}<k_{1}+\epsilon$. As we work here under the assumption that $k_{2}<k_{1}+\epsilon$, it follows that point $f$ lies to the left of point $e$. From the graph it should be clear that $n_{1}\left(k_{1}<\theta<k_{2}+\epsilon, k\right)=\frac{1}{2}+\frac{\epsilon-k_{1}+\theta-\epsilon}{4 \epsilon}=\frac{2 \epsilon+\theta-k_{1}}{4 \epsilon}$ and that $n_{2}\left(k_{1}<\theta<k_{2}+\epsilon, k\right)$ $=\frac{k_{1}-\theta+\epsilon}{4 \epsilon}-\frac{k_{2}-\theta}{4 \epsilon}=\frac{k_{1}+\epsilon-k_{2}}{4 \epsilon}$.

In case $(\mathrm{v})$ point $f$ lies to the left of point $a$. From above it should be clear that $n_{1}\left(k_{2}+\epsilon<\theta<k_{1}+2 \epsilon, k\right)=\frac{2 \epsilon+\theta-k_{1}}{4 \epsilon}$, and that $n_{2}\left(k_{2}+\epsilon<\theta<k_{1}+2 \epsilon, k\right)=\frac{k_{1}+2 \epsilon-\theta}{4 \epsilon}$.

In case (vi) point $e$ (see Figure 3 ) lies to the left of point $a$. Therefore $n_{1}\left(k_{1}+2 \epsilon<\right.$ $\theta, k)=1$ and $n_{2}\left(k_{1}+2 \epsilon<\theta, k\right)=0$. Q.E.D.

LEMMA 4 For any $k$ that solves equations (4) and (5) and for which $k_{2} \in\left(k_{1}-\right.$ $\left.\epsilon, k_{1}+\epsilon\right)$, one has $h\left(s_{2}^{i}, k\right)<0$ if $s_{2}^{i}<k_{2}$ and $h\left(s_{2}^{i}, k\right)>0$ if $s_{2}^{i} \in\left(k_{2}, k_{1}+\epsilon\right)$.

Proof: Since

$$
h\left(s_{2}^{i}, k\right)=s_{2}^{i}+\int_{s_{2}^{i}-\epsilon}^{s_{2}^{i}+\epsilon}\left[\gamma n_{1}(\theta, k)+n_{2}(\theta, k)\right] d \theta-1-\Delta,
$$

Leibnitz's rule implies that

$$
\frac{\partial h\left(s_{2}^{i}, k\right)}{\partial s_{2}^{i}}=1+\left[\gamma n_{1}\left(s_{2}^{i}+\epsilon, k\right)+n_{2}\left(s_{2}^{i}+\epsilon, k\right)-\left(\gamma n_{1}\left(s_{2}^{i}-\epsilon, k\right)+n_{2}\left(s_{2}^{i}-\epsilon, k\right)\right)\right] .
$$

We have shown in Lemma 3 that $n_{1}(\cdot)$ is weakly increasing in $\theta$ and therefore a sufficient condition for $h(\cdot)$ to be strictly increasing is that

$$
n_{2}\left(s_{2}^{i}+\epsilon, k\right) \geq n_{2}\left(s_{2}^{i}-\epsilon, k\right) .
$$

By Lemma $3, n_{2}(\cdot)$ is weakly increasing in $\theta$ for all $\theta \leq k_{2}+\epsilon$ and hence $h\left(s_{2}^{i}, k\right)$ is a strictly increasing function in $s_{2}^{i}$ for all $s_{2}^{i} \leq k_{2}$. Since $k$ solves the equations 
(4) and (5), $h\left(k_{2}, k\right)=0$ and we conclude that $h\left(s_{2}^{i}, k\right)<0$ if $s_{2}^{i}<k_{2}$.

Next, consider $s_{2}^{i} \in\left(k-2, k_{1}+\epsilon\right)$. Since $h\left(k_{2}, k\right)=0$, one can rewrite $h\left(s_{2}^{i}, k\right)$ as $h\left(s_{2}^{i}, k\right)=\left(s_{2}^{i}-k_{2}\right)+\gamma\left[E\left(n_{1} \mid s_{2}^{i}, k\right)-E\left(n_{1} \mid s_{2}^{i}=k_{2}, k\right)\right]+\left[E\left(n_{2} \mid s_{2}^{i}, k\right)-E\left(n_{2} \mid s_{2}^{i}=k_{2}, k\right)\right]$.

As $s_{2}^{i}>k_{2}$, the first term is positive. Since, by Lemma $3, n_{1}(\theta, k)$ is weakly increasing in $\theta$, Leibnitz's rule implies that $E\left(n_{1} \mid s_{2}^{i}, k\right)$ is weakly increasing in $s_{2}^{i}$. Hence $\left[E\left(n_{1} \mid s_{2}^{i}, k\right)-E\left(n_{1} \mid s_{2}^{i}=k_{2}, k\right)\right] \geq 0$. Thus a sufficient condition for $h\left(s_{2}^{i}, k\right)>0$ is that

$$
\left[E\left(n_{2} \mid s_{2}^{i}, k\right)-E\left(n_{2} \mid s_{2}^{i}=k_{2}, k\right)\right] \geq 0
$$

To prove that condition (6) is satisfied, we establish below that (i) $E\left(n_{2} \mid s_{2}^{i}, k\right)$ is a concave function in $s_{2}^{i}$ for all $s_{2}^{i} \in\left(k_{2}, k_{1}+\epsilon\right)$, and that (ii) $E\left(n_{2} \mid s_{2}^{i}=k_{1}+\epsilon, k\right)=$ $E\left(n_{2} \mid s_{2}^{i}=k_{2}, k\right)$. By Leibnitz's rule,

$$
\frac{\partial E\left(n_{2} \mid s_{2}^{i}, k\right)}{\partial s_{2}^{i}}=\frac{1}{2 \epsilon}\left[n_{2}\left(s_{2}^{i}+\epsilon, k\right)-n_{2}\left(s_{2}^{i}-\epsilon, k\right)\right],
$$

and thus

$$
\frac{\partial^{2} E\left(n_{2} \mid s_{2}^{i}, k\right)}{\partial\left(s_{2}^{i}\right)^{2}}=\frac{1}{2 \epsilon}\left[\frac{\partial n_{2}\left(s_{2}^{i}+\epsilon, k\right)}{\partial s_{2}^{i}}-\frac{\partial n_{2}\left(s_{2}^{i}-\epsilon, k\right)}{\partial s_{2}^{i}}\right] .
$$

Using the facts that $k_{2}+\epsilon<s_{2}^{i}+\epsilon<k_{1}+2 \epsilon, k_{2}-\epsilon<s_{2}^{i}-\epsilon<k_{1}$, and Lemma 3 , it is easy to check that $\frac{\partial^{2} E\left(n_{1} \mid s_{2}^{i}, k\right)}{\partial\left(s_{2}^{i}\right)^{2}}=-\frac{1}{4 \epsilon^{2}}$.

We are left to show that $E\left(n_{2} \mid s_{2}^{i}=k_{1}+\epsilon, k\right)=E\left(n_{2} \mid s_{2}^{i}=k_{2}, k\right)$. Using Lemma 3 , one has

$$
E\left(n_{2} \mid s_{2}^{i}=k_{1}+\epsilon, k\right)=\frac{1}{2 \epsilon} \int_{k_{1}}^{k_{2}+\epsilon} \frac{k_{1}+\epsilon-k_{2}}{4 \epsilon} d \theta+\frac{1}{2 \epsilon} \int_{k_{2}+\epsilon}^{k_{1}+2 \epsilon} \frac{2 \epsilon+k_{1}-\theta}{4 \epsilon} d \theta,
$$

and

$$
E\left(n_{2} \mid s_{2}^{i}=k_{2}, k\right)=\frac{1}{2 \epsilon} \int_{k_{2}-\epsilon}^{k_{1}} \frac{\epsilon-k_{2}+\theta}{4 \epsilon} d \theta+\frac{1}{2 \epsilon} \int_{k_{1}}^{k_{2}+\epsilon} \frac{k_{1}+\epsilon-k_{2}}{4 \epsilon} d \theta .
$$

Thus

$E\left(n_{2} \mid s_{2}^{i}=k_{1}+\epsilon, k\right)-E\left(n_{2} \mid s_{2}^{i}=k_{2}, k\right)=\frac{1}{8 \epsilon^{2}}\left[\int_{k_{2}+\epsilon}^{k_{1}+2 \epsilon}\left(2 \epsilon+k_{1}-\theta\right) d \theta-\int_{k_{2}-\epsilon}^{k_{1}}\left(\epsilon-k_{2}+\theta\right) d \theta\right]$. 
Integrating this last expression shows that $E\left(n_{2} \mid s_{2}^{i}=k_{1}+\epsilon, k\right)-E\left(n_{2} \mid s_{2}^{i}=\right.$ $\left.k_{2}, k\right)=0$. Q.E.D.

Let $\Sigma^{0}$ be the set of all strategies. Let $\Sigma^{n}$ be the set of all strategies that are undominated after $n$ rounds of iterative elimination of dominated strategies. Let $\sigma^{n} \in \Sigma^{n}$. Let $\underline{s}_{t}^{n}\left(\sigma^{n}\right)$ be the supremum below which $\sigma^{n}$ prescribes all players to refrain from investing with positive probability at time $t$. Let $\underline{s}_{t}^{n}=\inf \left\{\underline{s}_{t}^{n}\left(\sigma^{n}\right) \mid\right.$ $\left.\sigma^{n} \in \Sigma^{n}\right\}$. Call $\underline{s}^{n}=\left(\underline{s}_{1}^{n}, \underline{s}_{2}^{n}\right)$ the strategy in which all players invest at time one if and only if $s_{1}^{i}>\underline{s}_{1}^{n}$ and in which all active players invest at time two if and only if $s_{2}^{i}>\underline{s}_{2}^{n}$. Let

$$
\begin{gathered}
\hat{g}\left(s_{1}^{i}, \hat{\sigma}^{n}, \sigma^{n}\right) \equiv\left(s_{1}^{i}-1\right)\left(1-\frac{\tau}{2}\left(I_{\left\{h\left(s_{1}^{i}-\epsilon, \sigma^{n}\right)>0\right\}}+I_{\left\{h\left(s_{1}^{i}+\epsilon, \sigma^{n}\right)>0\right\}}\right)\right) \\
+\frac{1}{2} E_{2}\left(n_{1} \mid \hat{\sigma}^{n}, s_{1}^{i}-\epsilon\right)\left(1-\tau I_{\left\{h\left(s_{1}^{i}-\epsilon, \sigma^{n}\right)>0\right\}}\right)+\frac{1}{2} E_{2}\left(n_{1} \mid \hat{\sigma}^{n}, s_{1}^{i}+\epsilon\right)\left(1-\tau I_{\left\{h\left(s_{1}^{i}+\epsilon, \sigma^{n}\right)>0\right\}}\right) \\
+\frac{1}{2} E_{2}\left(n_{2} \mid \hat{\sigma}^{n}, s_{1}^{i}-\epsilon\right)\left(\alpha-\tau I_{\left\{h\left(s_{1}^{i}-\epsilon, \sigma^{n}\right)>0\right\}}\right)+\frac{1}{2} E_{2}\left(n_{2} \mid \hat{\sigma}^{n}, s_{1}^{i}+\epsilon\right)\left(\alpha-\tau I_{\left\{h\left(s_{1}^{i}+\epsilon, \sigma^{n}\right)>0\right\}}\right) \\
-\frac{\tau}{2}\left(I_{\left\{h\left(s_{1}^{i}-\epsilon, \sigma^{n}\right)>0\right\}}(-\epsilon-\Delta)+I_{\left\{h\left(s_{1}^{i}+\epsilon, \sigma^{n}\right)>0\right\}}(\epsilon-\Delta)\right),
\end{gathered}
$$

where $I_{\{\cdot\}}$ denotes the indicator function, and $\hat{\sigma}^{n} \in \Sigma^{n}$. We first state and prove the following lemma.

LEMma 5 If $\alpha \geq \tau, g\left(s_{1}^{i}, \underline{s}^{n}\right) \geq g\left(s_{1}^{i}, \sigma^{n}\right) \forall s_{1}^{i}$ and $\forall \sigma^{n} \in \Sigma^{n}$.

Proof: Observe that

$$
g\left(s_{1}^{i}, \underline{s}^{n}\right)-\hat{g}\left(s_{1}^{i}, \sigma^{n}, \underline{s}^{n}\right)=\frac{1}{2} \sum_{s_{2}^{i} \in\left\{s_{1}^{i}-\epsilon, s_{1}^{i}+\epsilon\right\}}\left\{\left[E_{2}\left(n_{1} \mid \underline{s}^{n}, s_{2}^{i}\right)\right.\right.
$$

$$
\left.\left.-E_{2}\left(n_{1} \mid \sigma^{n}, s_{2}^{i}\right)\right]\left(1-\tau I_{\left\{h\left(s_{2}^{i}, \underline{s}^{n}\right)>0\right\}}\right)+\left[E_{2}\left(n_{2} \mid \underline{s}^{n}, s_{2}^{i}\right)-E_{2}\left(n_{2} \mid \sigma^{n}, s_{2}^{i}\right)\right]\left(\alpha-\tau I_{\left\{h\left(s_{2}^{i}, \underline{s}^{n}\right)>0\right\}}\right)\right\} .
$$

For each $s_{2}^{i}$, define the expression between $\{\ldots\}$ of the above equation as

$$
f\left(s_{2}^{i}, \sigma^{n}\right) \equiv\left(1-\tau I_{\left\{h\left(s_{2}^{i}, \underline{s}^{n}\right)>0\right\}}\right) m\left(s_{2}^{i}, \sigma^{n}\right)+\left(\alpha-\tau I_{\left\{h\left(s_{2}^{i}, \underline{s}^{n}\right)>0\right\}}\right) m^{\prime}\left(s_{2}^{i}, \sigma^{n}\right),
$$

where $m\left(s_{2}^{i}, \sigma^{n}\right)$ and $m^{\prime}\left(s_{2}^{i}, \sigma^{n}\right)$ are defined as

$$
m\left(s_{2}^{i}, \sigma^{n}\right) \equiv \frac{1}{2 \epsilon} \int_{s_{2}^{i}-\epsilon}^{s_{2}^{i}+\epsilon}\left(n_{1}\left(\theta, \underline{s}^{n}\right)-n_{1}\left(\theta, \sigma^{n}\right)\right) d \theta
$$




$$
m^{\prime}\left(s_{2}^{i}, \sigma^{n}\right) \equiv \frac{1}{2 \epsilon} \int_{s_{2}^{i}-\epsilon}^{s_{2}^{i}+\epsilon}\left(n_{2}\left(\theta, \underline{s}^{n}\right)-n_{2}\left(\theta, \sigma^{n}\right)\right) d \theta .
$$

As all players with a $s_{1}^{i}>\underline{s}_{1}^{n}$ invest under $\underline{s}^{n}$, it follows that $m\left(s_{2}^{i}, \sigma^{n}\right) \geq 0$ for all $s_{2}^{i}$ and for all $\sigma^{n}$. Hence, if $m^{\prime}\left(s_{2}^{i}, \sigma^{n}\right) \geq 0$, then $f\left(s_{2}^{i}, \sigma^{n}\right)$ is positive. Thus suppose that $m^{\prime}\left(s_{2}^{i}, \sigma^{n}\right)<0$. Then $f\left(s_{2}^{i}, \sigma^{n}\right)$ is bounded below by $(1-$ $\left.\tau I_{\left\{h\left(s_{2}^{i}, \underline{s}^{n}\right)>0\right\}}\right)\left(m\left(s_{2}^{i},\left(\sigma_{1}^{n}, \underline{s}_{2}^{n}\right)\right)+m^{\prime}\left(s_{2}^{i},\left(\sigma_{1}^{n}, \underline{s}_{2}^{n}\right)\right)\right)$. Note that

$$
\begin{gathered}
m\left(s_{2}^{i},\left(\sigma_{1}^{n}, \underline{s}_{2}^{n}\right)\right)+m^{\prime}\left(s_{2}^{i},\left(\sigma_{1}^{n}, \underline{s}_{2}^{n}\right)\right)= \\
\frac{1}{2 \epsilon} \int_{s_{2}^{i}-\epsilon}^{s_{2}^{i}+\epsilon}\left[\left(n_{1}\left(\theta, \underline{s}^{n}\right)+n_{2}\left(\theta, \underline{s}^{n}\right)\right)-\left(n_{1}\left(\theta,\left(\sigma_{1}^{n}, \underline{s}_{2}^{n}\right)\right)+n_{2}\left(\theta,\left(\sigma_{1}^{n}, \underline{s}_{2}^{n}\right)\right)\right)\right] d \theta,
\end{gathered}
$$

which is nonnegative and we conclude that $g\left(s_{1}^{i}, \underline{s}^{n}\right) \geq \hat{g}\left(s_{1}^{i}, \sigma^{n}, \underline{s}^{n}\right)$. As $g\left(s_{1}^{i}, \sigma^{n}\right)$ prescribes optimal time-two behavior, trivially $\hat{g}\left(s_{1}^{i}, \hat{\sigma}^{n}, \underline{s}^{n}\right) \geq g\left(s_{1}^{i}, \sigma^{n}\right)$, and thus $g\left(s_{1}^{i}, \underline{s}^{n}\right) \geq g\left(s_{1}^{i}, \sigma^{n}\right) \forall \sigma^{n} \in \Sigma^{n}$. Q.E.D.

Let $\bar{s}_{t}^{n}\left(\sigma^{n}\right)$ be the infimum above which $\sigma^{n}$ prescribes all players to invest at time $t$ with probability 1 . Let $\bar{s}_{t}^{n}=\sup \left\{\bar{s}_{t}^{n}\left(\sigma^{n}\right) \mid \sigma^{n} \in \Sigma^{n}\right\}$. Call $\bar{s}^{n}=\left(\bar{s}_{1}^{n}, \bar{s}_{2}^{n}\right)$ the strategy in which all players invest at time one if and only if $s_{1}^{i}>\bar{s}_{1}^{n}$ and in which all active players invest at time two if and only if $s_{2}^{i}>\bar{s}_{2}^{n}$.

\section{Proof of Proposition 2:}

It follows from Lemma (5) that, conditional on $s_{1}^{i}$, investing in the first period is dominated after $n+1$ rounds of iterative elimination of dominated strategies if and only if $g\left(s_{1}^{i}, \underline{s}^{n}\right)<0$.

Furthermore, $\left(n_{1}+n_{2}\right)\left(\theta, \underline{s}^{n}\right) \geq\left(n_{1}+n_{2}\right)\left(\theta, \sigma^{n}\right)$ for all $\sigma^{n} \in \Sigma^{n}$ because $\underline{s}^{n}$ prescribes an active player to invest whenever investing is not dominated after $n$ rounds of iterative elimination of dominated strategies. Using this fact, it is easy to check that $h\left(s_{2}^{i}, \underline{s}^{n}\right) \geq h\left(s_{2}^{i}, \sigma^{n}\right)$ for all $\sigma^{n} \in \Sigma^{n}$. Hence, conditional on $s_{2}^{i}$, investing in the second period is dominated after $n+1$ rounds of iterative elimination if and only if $h\left(s_{2}^{i}, \underline{s}^{n}\right)<0$. We conclude that when iteratively deleting dominated strategies from below, we can restrict attention to switching strategies $\underline{s}^{n}$.

We now show by induction that $\underline{s}_{1}^{n}$ and $\underline{s}_{2}^{n}$ are increasing sequences. Trivially, $\left(\underline{s}_{1}^{0}, \underline{s}_{2}^{0}\right)=(-\infty,-\infty)$. Because it is a dominant strategy not to invest for sufficiently low first- and second-period signals, $\left(\underline{s}_{1}^{1}, \underline{s}_{2}^{1}\right)>>\left(\underline{s}_{1}^{0}, \underline{s}_{2}^{0}\right)$. We are left to 
show that, $\underline{s}^{n-2} \leq \underline{s}^{n-1}$, implies that $\underline{s}^{n-1} \leq \underline{s}^{n} \cdot{ }^{19}$

We first show that $\underline{s}_{1}^{n-1} \leq \underline{s}_{1}^{n}$. By definition of $\underline{s}_{1}^{n-1}$, we know that $g\left(\underline{s}_{1}^{n-1}, \underline{s}^{n-2}\right)=0$. As $\underline{s}^{n-1} \in \Sigma^{n-2}$, from Lemma (5) we know that $g\left(\underline{s}_{1}^{n-1}, \underline{s}^{n-2}\right) \geq g\left(\underline{s}_{1}^{n-1}, \underline{s}^{n-1}\right)$. $\underline{s}_{1}^{n}$ cannot be strictly lower than $\underline{s}_{1}^{n-1}$ because, by definition of $\underline{s}_{1}^{n-1}, \forall s_{1}^{i}<\underline{s}_{1}^{n-1}$ all strategies which prescribe player $i$ to invest at time one with positive probability are dominated ones. As $g\left(\underline{s}_{1}^{n-1}, \underline{s}^{n-1}\right) \leq 0$ and as there exists some $\tilde{s}_{1}^{i}$ for which it is a dominant strategy to invest (i.e. for which $g\left(\tilde{s}_{1}^{i}, \underline{s}^{n-1}\right)>0$ ), continuity of $g(\cdot)$ implies that there exists $\underline{s}_{1}^{n}$ such that $g\left(\underline{s}_{1}^{n}, \underline{s}^{n-1}\right)=0$.

Next, we show that $\underline{s}_{2}^{n-1} \leq \underline{s}_{2}^{n}$. It is obvious that $E_{2}\left(n_{1}+n_{2} \mid s_{2}^{i}, \underline{s}^{n-2}\right) \geq E_{2}\left(n_{1}+\right.$ $\left.n_{2} \mid s_{2}^{i}, \underline{s}^{n-1}\right)$. Therefore,

$\underline{s}_{2}^{n-1}+E_{2}\left(n_{1}+n_{2} \mid \underline{s}_{2}^{n-1}, \underline{s}^{n-1}\right)-1-\Delta \leq \underline{s}_{2}^{n-1}+E_{2}\left(n_{1}+n_{2} \mid \underline{s}_{2}^{n-1}, \underline{s}^{n-2}\right)-1-\Delta=0$

This implies that $\underline{s}_{2}^{n-1} \leq \underline{s}_{2}^{n}$ because $s_{2}^{i}+E_{2}\left(n_{1}+n_{2} \mid s_{2}^{i}, \underline{s}^{n-1}\right)-1-\Delta$ is strictly increasing in $s_{2}^{i}$ and by definition

$$
\underline{s}_{2}^{n}+E_{2}\left(n_{1}+n_{2} \mid \underline{s}_{2}^{n}, \underline{s}^{n-1}\right)-1-\Delta=0 .
$$

Hence, as $n \rightarrow \infty, \underline{s}^{n}$ converges to some cutoff vector $\underline{s}$ that satisfies $g\left(\underline{s}_{1}, \underline{s}\right)=0$ and $h\left(\underline{s}_{2}, \underline{s}\right)=0$. Using reasoning that mirrors the one for $\underline{s}^{n}$, shows that $\bar{s}^{n}$ is a decreasing sequence that, as $n \rightarrow \infty$, converges to a cutoff vector $\bar{s}$ that satisfies $g\left(\bar{s}_{1}, \bar{s}\right)=0$ and $h\left(\bar{s}_{2}, \bar{s}\right)=0$.

We are left to show that $\underline{s}=\bar{s}$. Suppose otherwise. Both $\underline{s}$ and $\bar{s}$ solve the following system of equations.

$$
\begin{aligned}
& g\left(k_{1}, k\right)=0, \\
& h\left(k_{2}, k\right)=0 .
\end{aligned}
$$

First, observe that if $\underline{s}_{1}=\bar{s}_{1}$ then $\underline{s}_{2}=\bar{s}_{2}$ because $h\left(k_{2},\left(k_{1}, k_{2}\right)\right)$ is strictly increasing in $k_{2}$. Thus, $\underline{s}_{1}<\bar{s}_{1} . \underline{s}_{2}$ and $\bar{s}_{2}$ must be chosen such that $h\left(\underline{s}_{2}, \underline{s}\right)$ and $h\left(\bar{s}_{2}, \bar{s}\right)=0$, which implies that

$$
\left(\bar{s}_{2}-\underline{s}_{2}\right)=E_{2}\left(n_{1}+n_{2} \mid \underline{s}_{2}, \underline{s}\right)-E_{2}\left(n_{1}+n_{2} \mid \bar{s}_{2}, \bar{s}\right)
$$

To gain some insight about $E_{2}\left(n_{1}+n_{2} \mid \cdot\right)$ 's consider the following two pair of cutoffs $\left(k_{1}^{\prime}, k_{2}\right)$ and $\left(k_{1}^{\prime \prime}, k_{2}\right)$. Both strategies possess the same second-period cutoffs but

\footnotetext{
${ }^{19}$ When comparing two vectors, we use $\leq$ to indicate that for all $i$, the $i$ th component of the first vector is $\leq$ to the $i$ th component of the second vector.
} 
suppose without loss of generality that $k_{1}^{\prime}<k_{1}^{\prime \prime}$. Consider any arbitrary $\left(s_{1}^{i}, s_{2}^{i}\right)$. Clearly, if player $i$ invests in either period under strategy $\left(k_{1}^{\prime \prime}, k_{2}\right)$, she also invests under strategy $\left(k_{1}^{\prime}, k_{2}\right)$. Hence, $E_{2}\left(n_{1}+n_{2} \mid k_{2},\left(k_{1}, k_{2}\right)\right)$ is weakly increasing in $k_{2}-k_{1}$. Hence a necessary condition for for equation (10) to hold is that

$$
\bar{s}_{2}-\bar{s}_{1}<\underline{s}_{2}-\underline{s}_{1}
$$

Now consider a player whose $s_{2}^{i}=k_{1}+\epsilon$. Consider two different second-period cutoff levels $k_{2}^{\prime}$ and $k_{2}^{\prime \prime}$, and suppose without loss of generality that $k_{2}^{\prime}<k_{2}^{\prime \prime}$. Consider any $s_{1}^{i}<k_{1}$. Clearly, if player $i$ invests at time two under $\left(k_{1}, k_{2}^{\prime \prime}\right)$, she will also do so under $\left(k_{1}, k_{2}^{\prime}\right)$. Hence, $E_{2}\left(n_{2} \mid k_{1}+\epsilon,\left(k_{1}, k_{2}\right)\right)$ is weakly decreasing in $k_{2}-k_{1}$. The same logic can be applied to $E_{2}\left(n_{2} \mid k_{1}-\epsilon,\left(k_{1}, k_{2}\right)\right)$. Thus from (11) follows that

$$
E_{2}\left(n_{2} \mid \bar{s}_{1}+\epsilon, \bar{s}\right) \geq E_{2}\left(n_{2} \mid \underline{s}_{1}+\epsilon, \underline{s}\right) \text { and } E_{2}\left(n_{2} \mid \bar{s}_{1}-\epsilon, \bar{s}\right) \geq E_{2}\left(n_{2} \mid \underline{s}_{1}-\epsilon, \underline{s}\right) .
$$

We also know that $\underline{s}_{1}$ and $\bar{s}_{1}$ must be chosen such that $g\left(\underline{s}_{1}, \underline{s}\right)=g\left(\bar{s}_{1}, \bar{s}\right)=0$. Note that

$$
\begin{aligned}
g\left(\bar{s}_{1}, \bar{s}\right)-\hat{g}\left(\underline{s}_{1}, \underline{s}, \bar{s}\right)=\left(\bar{s}_{1}-\underline{s}_{1}\right)\left(1-\frac{\tau}{2} I_{\left\{h\left(\bar{s}_{1}+\epsilon, \bar{s}\right)>0\right\}}-\frac{\tau}{2} I_{\left\{h\left(\bar{s}_{1}-\epsilon, \bar{s}\right)>0\right\}}\right) \\
+\frac{1}{2}\left(E_{2}\left(n_{2} \mid \bar{s}_{1}+\epsilon, \bar{s}\right)-E_{2}\left(n_{2} \mid \underline{s}_{1}+\epsilon, \underline{s}\right)\right)\left(\alpha-\tau I_{\left\{h\left(\bar{s}_{1}+\epsilon, \bar{s}\right)>0\right\}}\right) \\
+\frac{1}{2}\left(E_{2}\left(n_{2} \mid \bar{s}_{1}-\epsilon, \bar{s}\right)-E_{2}\left(n_{2} \mid \underline{s}_{1}-\epsilon, \underline{s}\right)\right)\left(\alpha-\tau I_{\left\{h\left(\bar{s}_{1}-\epsilon, \bar{s}\right)>0\right\}}\right) .
\end{aligned}
$$

From (12) and from the fact that $\bar{s}_{1}>\underline{s}_{1}$, it follows that $g\left(\bar{s}_{1}, \bar{s}\right)>\hat{g}\left(\underline{s}_{1}, \underline{s}, \bar{s}\right)$. As $\hat{g}\left(\underline{s}_{1}, \underline{s}, \bar{s}\right) \geq g\left(\underline{s}_{1}, \underline{s}\right)$ it follows that, under $(11), g\left(\bar{s}_{1}, \bar{s}\right)>g\left(\underline{s}_{1}, \underline{s}\right)$, a contradiction. Q.E.D.

\section{Proof of Proposition 3:}

In an immediate investment equilibrium no player invests in the second period. Hence,

$$
h\left(s_{2}^{i}, k\right)=s_{2}^{i}+\gamma E\left(n_{1} \mid s_{2}^{i}, k\right)-1-\Delta .
$$

It follows from the derivation of $n_{1}(\theta, k)$ in Lemma 3 that $n_{1}(\theta, k)$ is weakly increasing in the fundamental $\theta$. Thus,

$$
E\left(n_{1} \mid s_{2}^{i}, k\right)=\frac{1}{2 \epsilon} \int_{s_{2}^{i}-\epsilon}^{s_{2}^{i}+\epsilon} n_{1}(\theta, k) d \theta
$$


is weakly increasing in $s_{2}^{i}$, and hence $h\left(s_{2}^{i}, k\right)$ is strictly increasing in an immediate investment equilibrium. Therefore, there exists a unique $k_{2}$ such that $h\left(s_{2}^{i}, k\right) \leq 0$ if and only if $s_{2}^{i} \leq k_{2}$. By definition, we look for an equilibrium in which $k_{2} \geq k_{1}+\epsilon$, which implies that $h\left(s_{2}^{i}=k_{1}+\epsilon, k\right) \leq 0$. Hence, the gain of waiting must be equal to zero. Therefore, $k_{1}$ must be set such that a player who possesses a signal $s_{1}^{i}=k_{1}$ is indifferent between investing and not investing. Thus $k_{1}$ solves the following equation

$$
k_{1}+E\left(n_{1} \mid s_{1}^{i}=k_{1}, k\right)-1=0 .
$$

Using the function $n_{1}(\theta, k)$, derived in Lemma 3 , and the fact that

$$
E\left(n_{1} \mid s_{1}^{i}=k_{1}, k\right)=\frac{1}{4 \epsilon} \int_{k_{1}-2 \epsilon}^{k_{1}+2 \epsilon} n_{1}(\theta, k) d \theta
$$

it is easy to verify that $E\left(n_{1} \mid s_{1}^{i}=k_{1}, k\right)=\frac{1}{2}$. Thus, in an immediate investment equilibrium $k_{1}=\frac{1}{2}$. Using this fact to rewrite the condition that no player has an incentive to invest in the second period, i.e. that $h\left(s_{2}^{i}=k_{1}+\epsilon, k\right) \leq 0$, gives

$$
\frac{1}{2}+\epsilon+\gamma E\left(n_{1} \mid s_{2}^{i}=k_{1}+\epsilon, k\right) \leq 1+\Delta .
$$

Similar, using $n_{1}(\theta, k)$ and the fact that

$$
E\left(n_{1} \mid s_{2}^{i}=k_{1}+\epsilon, k\right)=\frac{1}{2 \epsilon} \int_{k_{1}}^{k_{1}+2 \epsilon} n_{1}(\theta, k) d \theta,
$$

it is easy to verify that $E\left(n_{1} \mid s_{2}^{i}=k_{1}+\epsilon, k\right)=\frac{3}{4}$. Substituting this into equation (13) and rewriting yields $\Delta \geq-\frac{1}{2}+\epsilon+\frac{3}{4} \gamma$, which is a necessary condition for an immediate investment equilibrium to exist. Because we already established that $h\left(s_{2}^{i}, k\right)$ is strictly increasing, it suffices to show that $g(\cdot)$ is (weakly) increasing to show that an immediate investment equilibrium exists whenever $\Delta \geq-\frac{1}{2}+\epsilon+\frac{3}{4} \gamma$. First, observe that for all $s_{1}^{i}<k_{2}-\epsilon$, one has

$$
g\left(s_{1}^{i}, k\right)=s_{1}^{i}+E\left(n_{1} \mid s_{1}^{i}, k\right)-1,
$$

which is strictly increasing in $s_{1}^{i}$ because $E\left(n_{1} \mid s_{1}^{i}, k\right)$ is weakly increasing in $s_{1}^{i}$. Second, for all $k_{2}-\epsilon<s_{1}^{i}<k_{2}+\epsilon$,

$$
g\left(s_{1}^{i}, k\right)=s_{1}^{i}+E\left(n_{1} \mid s_{1}^{i}, k\right)-1-\frac{\tau}{2} h\left(s_{1}^{i}+\epsilon, k\right) .
$$

Using Lemma (2) and equation (1), one can rewrite the above equation as $g\left(s_{1}^{i}, k\right)=\left(1-\frac{\tau}{2}\right) s_{1}^{i}+\frac{1}{2}\left[E\left(n_{1} \mid s_{2}^{i}=s_{1}^{i}-\epsilon, k\right)+(1-\tau \gamma) E\left(n_{1} \mid s_{2}^{i}=s_{1}^{i}+\epsilon, k\right)-\tau \epsilon-(2-\tau)+\tau \Delta\right]$. 
Since $E\left(n_{1} \mid s_{2}^{i}=s_{1}^{i}-\epsilon, k\right)$ and $E\left(n_{1} \mid s_{2}^{i}=s_{1}^{i}+\epsilon, k\right)$ are weakly increasing in $s_{1}^{i}$, and $\tau, \gamma \leq 1, g\left(s_{1}^{i}, k\right)$ is strictly increasing in $s_{1}^{i}$ in this subcase. Third, for all $k_{2}+\epsilon<s_{1}^{i}$, one has

$$
g\left(s_{1}^{i}, k\right)=s_{1}^{i}+E\left(n_{1} \mid s_{1}^{i}, k\right)-1-\frac{\tau}{2}\left[h\left(s_{1}^{i}-\epsilon, k\right)+h\left(s_{1}^{i}+\epsilon, k\right)\right] .
$$

Rewriting this equation using Lemma (2) and equation (1) yields

$g\left(s_{1}^{i}, k\right)=(1-\tau) s_{1}^{i}+\frac{(1-\tau \gamma)}{2}\left[E\left(n_{1} \mid s_{2}^{i}=s_{1}^{i}-\epsilon\right)+E\left(n_{1} \mid s_{2}^{i}=s_{1}^{i}+\epsilon\right)\right]-(1-\tau)+\tau \Delta$.

Since $E\left(n_{1} \mid s_{2}^{i}=s_{1}^{i}-\epsilon\right)$ and $E\left(n_{1} \mid s_{2}^{i}=s_{1}^{i}+\epsilon\right)$ are weakly increasing in $s_{1}^{i}$, and $\tau, \gamma \leq 1, g\left(s_{1}^{i}, k\right)$ is weakly increasing in $s_{1}^{i}$ in this subcase. Q.E.D.

\section{Proof of Proposition 4:}

Rewriting (4) and (5) using the fact that $k_{1}-\epsilon<k_{2}<k_{1}+\epsilon$ in an informative waiting equilibrium gives

$$
\begin{gathered}
k_{1}+\frac{1}{2}+\left(\frac{\alpha}{8 \epsilon}\right)\left(k_{1}+\epsilon-k_{2}\right)-1-\frac{\tau}{2}\left\{k_{1}+\epsilon+\frac{3 \gamma}{4}+\frac{1}{16 \epsilon^{2}}\left(k_{1}+\epsilon-k_{2}\right)\left(k_{2}+3 \epsilon-k_{1}\right)-1-\Delta\right\}=0, \\
k_{2}+\gamma\left\{\frac{1}{4}+\frac{1}{4 \epsilon}\left(k_{2}+\epsilon-k_{1}\right)+\frac{1}{16 \epsilon^{2}}\left(k_{1}+\epsilon-k_{2}\right)\left(k_{2}+3 \epsilon-k_{1}\right)\right\}-1-\Delta=0 .
\end{gathered}
$$

Thus, (4) and (5) are a pair of quadratic equations, which is equivalent to a fourth order polynomial. Hence, there exists a routine procedure to solve this system of equations. Using mathematica to solve this system of equations shows that there are only two pair of roots $\left(k_{11}, k_{21}\right)$ and $\left(k_{21}, k_{22}\right)$. Rewriting, gives the expressions given in the proposition above. Because (4) and (5) are necessary conditions for an equilibrium, all informative waiting equilibria ar either of the form $\left(k_{11}, k_{21}\right)$ or $\left(k_{21}, k_{22}\right)$.

Observe that all roots are real if and only if $D \geq 0$. This requires that

$$
16 \epsilon-8+12 \gamma+[(2-\alpha)-(2-\tau) x]^{2} \geq 16 \Delta .
$$

Rewriting gives condition (a).

$\left(k_{11}, k_{21}\right)$ is a valid solution only if $k_{11}-\epsilon<k_{21}<k_{11}+\epsilon$, because otherwise the functional form of (4) and (5) would differ from the one used above. That is, we require that (i) $-\epsilon<k_{11}-k_{21}$ and that (ii) $k_{11}-k_{21}<\epsilon$. Using the fact that

$$
k_{11}-k_{21}=\epsilon[1-\alpha-(2-\tau) x+\sqrt{D}],
$$


condition (i) holds if and only if

$$
(2-\tau) x-(2-\alpha)<\sqrt{D}
$$

Note that this inequality is satisfied if either $(2-\alpha)>(2-\tau) x$ or if

$$
[(2-\tau) x-(2-\alpha)]^{2}<-16 \Delta+16 \epsilon-8+12 \gamma+[(2-\alpha)-(2-\tau) x]^{2} .
$$

Rewriting gives condition (b).

Using $k_{11}-k_{21}=\epsilon[1-\alpha-(2-\tau) x+\sqrt{D}]$, to rewrite condition (ii) gives

$$
\sqrt{D}<\alpha+(2-\tau) x .
$$

Squaring this inequality on both sides and rewriting yields

$$
-16 \Delta+16 \epsilon+12 \gamma-4(1+\alpha)-4 x(2-\tau)<0,
$$

which is equivalent to condition (c) in the proposition. Hence, conditions (a), (b), and $(\mathrm{c})$ are necessary conditions for $\left(k_{11}, k_{21}\right)$ to characterize an equilibrium.

Similar, $\left(k_{12}, k_{22}\right)$ is a valid solution only if both (i) $-\epsilon<k_{12}-k_{22}$ and (ii) $k_{12}-k_{22}<$ $\epsilon$ hold. Using the fact that $k_{12}-k_{22}=\epsilon[1-\alpha-(2-\tau) x-\sqrt{D}]$, condition (i) holds if and only if $\sqrt{D}<(2-\alpha)-(2-\tau) x$. Hence, condition (i) requires that $(2-\alpha)>(2-\tau) x$, which is condition $(\mathrm{d})$ in the proposition, and that $D<[(2-\alpha)-(2-\tau) x]^{2}$, which is equivalent to condition (e) in the proposition. We conclude that conditions (a), (d) and (e) are necessary conditions for $\left(k_{12}, k_{22}\right)$ to characterize an equilibrium. (Note also that $k_{12}-k_{22}=\epsilon[1-\alpha-(2-\tau) x-\sqrt{D}]<\epsilon$.) Hence, we have established that no other informative waiting equilibrium than the ones characterized in the proposition exist. To show that $\left(k_{11}, k_{21}\right)$ and $\left(k_{12}, k_{22}\right)$ are indeed equilibria under the above conditions, we are left to verify that (i) $h\left(s_{2}^{i}, k\right)<0$ for all $s_{2}^{i}<k_{2}$, (ii) $h\left(s_{2}^{i}, k\right)>0 \forall s_{2}^{i} \in\left(k_{2}, k_{1}+\epsilon\right]$, and that (iii) $g\left(s_{1}^{i}, k\right)<0$ if and only if $s_{1}^{i}<k_{1}$. Conditions (i) and (ii) follow from Lemma (4). The proof of Condition (iii) is available upon request. Q.E.D.

\section{Proof of Lemma 1:}

We start by proving the first statement. Suppose otherwise, i.e. there exists a symmetric switching equilibrium in which no player invests in the first period. Rewriting condition (5) gives

$$
h\left(s_{2}^{i}, k\right)=k_{2}+E\left(n_{2} \mid s_{2}^{i}=k_{2}, k\right)-1-\Delta=0 .
$$


It is easy to check that $E\left(n_{2} \mid s_{2}^{i}=k_{2}, k\right)=\frac{1}{2}$, and hence $k_{2}=\frac{1}{2}+\Delta$. Consider a player with a signal $s_{1}^{i}>k_{2}+3 \epsilon$. This player knows in equilibrium that all (other) players invest in the second period. Hence,

$$
g\left(s_{1}^{i}, k\right)=s_{1}^{i}+\alpha-1-\tau\left[s_{1}^{i}-\Delta\right] .
$$

Rewriting, yields $g\left(s_{1}^{i}, k\right)=(1-\tau) s_{1}^{i}-(1-\alpha)+\tau \Delta$. If $\tau<1$, then for all sufficiently high $s_{1}^{i}$ one has $g\left(s_{1}^{i}, k\right)>0$. Similar if $\alpha=\gamma=\tau=1$ and $\Delta>0$, then $g\left(s_{1}^{i}, k\right)=\Delta>0$. But if $g\left(s_{1}^{i}, k\right)>0$ a player has a strict incentive to invest in the first period, which contradicts the fact that all players refrain from investing in the first period.

We now prove the second statement. Recall that $E\left(n_{1} \mid s_{1}^{i}=k_{1}, k\right)=\frac{1}{2}$. Also, note that since $k_{2}<k_{1}-\epsilon$, a player with signal $s_{1}^{i}=k_{1}$ who waits will invest in the second period for certain. Using these facts and Lemma (2) to rewrite equilibrium conditions (4) and (5) gives:

$$
\begin{gathered}
k_{1}(1-\tau)+\frac{1}{2}(1-\tau \gamma)+(\alpha-\tau) E\left(n_{2} \mid s_{1}^{i}=k_{1}, k\right)-1+\tau(1+\Delta)=0 \\
k_{2}=1+\Delta-\gamma E\left(n_{1} \mid s_{2}^{i}=k_{2}, k\right)-E\left(n_{1} \mid s_{2}^{i}=k_{2}, k\right)
\end{gathered}
$$

Observe that any player with a signal $s_{2}^{i}<k_{2}$ does not invest in either period because in this case $s_{1}^{i} \leq s_{2}^{i}+\epsilon<k_{2}+\epsilon<k_{1}$. Hence, $E\left(n_{1}+n_{2} \mid s_{2}^{i}=k_{2}, k\right)=\frac{1}{2}$ and thus $E\left(\gamma n_{1}+n_{2} \mid s_{2}^{i}=k_{2}, k_{2}\right) \leq \frac{1}{2}$. Using this fact and equation (15), we conclude that $k_{2} \geq \frac{1}{2}+\Delta$.

Rewriting equation (14) shows that

$$
k_{1}=\frac{1}{1-\tau}\left\{\frac{1}{2}\left(1+\tau \gamma-\tau(1+\Delta)+(\tau-\alpha) E\left(n_{2} \mid s_{1}^{i}=k_{1}, k\right)\right)\right\} .
$$

First, suppose that $\alpha \geq \tau$. In this case

$$
k_{1} \leq \frac{1}{1-\tau}\left\{\frac{1}{2}(1+\tau \gamma-\tau(1+\Delta)\}\right.
$$

and since $k_{2} \geq \frac{1}{2}+\Delta$ a necessary condition for $k_{1}>k_{2}+\epsilon$ is that

$$
\left\{\frac{1}{2}(1+\tau \gamma)-\tau(1+\Delta)\right\} \geq(1-\tau)\left(\frac{1}{2}+\Delta+\epsilon\right) .
$$

This is equivalent to $0 \geq \Delta+\epsilon(1-\tau)+\frac{\tau}{2}(1-\gamma)$, a contradiction. 
We are left to consider the case in which $\alpha<\tau$. Observe that since $E\left(n_{1} \mid s_{1}^{i}=\right.$ $\left.k_{1}, k\right)=\frac{1}{2}$ and $n_{1}+n_{2} \leq 1, E\left(n_{2} \mid s_{1}^{i}=k_{1}, k\right) \leq \frac{1}{2}$. Hence,

$$
k_{1} \leq \frac{1}{1-\tau}\left\{\frac{1}{2}\left(1+\tau \gamma-\tau(1+\Delta)+(\tau-\alpha) \frac{1}{2}\right\}\right.
$$

Thus, a necessary condition for $k_{1}>k_{2}+\epsilon$ is that

$$
\left\{\frac{1}{2}\left(1+\tau \gamma-\tau(1+\Delta)+(\tau-\alpha) \frac{1}{2}\right\} \geq(1-\tau)\left(\frac{1}{2}+\Delta+\epsilon\right) .\right.
$$

Rewriting this condition establishes the Lemma. Q.E.D.

\section{Proof of Proposition 6:}

We know from Proposition 2 that the equilibrium is unique in this case. For all $\Delta \geq$ $\Delta^{b}$, the unique equilibrium is the immediate investment equilibrium characterized in Proposition 3. In this equilibrium a player invests in the first period if and only if he receives a signal $s_{1}^{i}>1 / 2$. For $\Delta<\Delta^{b}$ the unique equilibrium $\left(k_{1} 1, k_{2} 1\right)$ is characterized in Proposition 4. Differentiating $k_{11}$ and $k_{21}$ with respect to $\Delta$, one has

$$
\begin{gathered}
\frac{\partial k_{11}}{\partial \Delta}=\frac{1}{\sqrt{D}}(\alpha-x \tau)<0, \\
\frac{\partial k_{21}}{\partial \Delta}=\frac{1}{\sqrt{D}}(\alpha+8 \epsilon-x \tau)>0 .
\end{gathered}
$$

The Proposition thus follows from the fact that as $\Delta$ approaches $\Delta^{b}, k_{11}$ approaches $1 / 2$, which can be verified by substituting $\Delta^{b}$ into the expression for $k_{11}$. Q.E.D.

\section{Proof of Proposition 7:}

Define $\bar{s} \equiv\left(\frac{1}{4}+\epsilon\right)\left(\frac{1+\delta}{\delta}\right)$ and note that if $s=\bar{s}$ then $\Delta=\Delta^{b}$. As delta is increasing in $s$, we know that for all $s \geq \bar{s}$ the immediate investment equilibrium is played and hence no player invests in the second period. Furthermore, because $\frac{\partial \theta}{\partial s}=-\frac{1}{1+\delta}$ it is clear that the first period investment activity is strictly decreasing in the setup costs $s$ for all $s \geq \bar{s}$.

For $s<\bar{s}$, first period investment activity falls if

$$
\frac{\partial \theta}{\partial s}<\frac{\partial k_{11}}{\partial s}
$$


Differentiating and rewriting gives $\frac{-1}{1+\delta}<\frac{\delta}{(1+\delta) \sqrt{D}}(-4 \epsilon \tau)$, which can be rewritten as $D>\frac{16 \epsilon^{2} \delta^{4}}{(1+\delta)^{2}}$. Using the facts that $D$ is decreasing in $s, \delta<1$, and $\tau<1$, it is easy to see that the above holds since

$$
D>D(\bar{s})=(2-\tau)^{2} 16 \epsilon^{2}>\frac{\delta^{4}}{(1+\delta)^{2}} 16 \epsilon^{2} .
$$

Furthermore, it is straightforward to verify that $\frac{\partial k_{21}}{\partial s}>0$ and therefore second period investment activity declines in $s$ whenever it is strictly positive.

We are left to show that there exists parameter values for which an increase in $\delta$ increases early investment activity and reduces late investment activity. Let $\phi=\frac{\delta}{1+\delta}$. One has,

$$
\frac{\partial k_{11}}{\partial \phi}=\frac{1}{8}\left\{4 \epsilon(\sqrt{D}-8 \epsilon(1-\phi))-\frac{32 \epsilon \phi}{\sqrt{D}}\left(s+2 \epsilon^{2}(2-\phi)\right)\right\} .
$$

Evaluating the above at $s=\bar{s}$ and rewriting, using the fact that $\sqrt{D(\bar{s})}=(2-\phi) 4 \epsilon$, one has

$$
\left.\frac{\partial k_{11}}{\partial \phi}\right|_{s=\bar{s}}=\frac{-\left(\frac{1}{4}+\epsilon\right)}{2-\phi} .
$$

Thus,

$$
\left.\frac{\partial k_{11}}{\partial \delta}\right|_{s=\bar{s}}=\frac{-\left(\frac{1}{4}+\epsilon\right)}{2-\phi} \frac{1}{(1+\delta)^{2}}
$$

Note that $\left.\frac{\partial \theta}{\partial \delta}\right|_{s=\bar{s}}=\frac{\bar{s}}{(1+\delta)^{2}}=\frac{\left(\frac{1}{4}+\epsilon\right)}{(1+\delta)^{2}} \frac{\delta}{1+\delta}$. Hence, $\left.\frac{\partial k_{11}}{\partial \delta}\right|_{s=\bar{s}}<\left.\frac{\partial \theta}{\partial \delta}\right|_{s=\bar{s}}$. As the inequality is strict it also holds for some $s$ less than but sufficiently close to $\bar{s}$. Hence, for such $s$ as player become more patient, more players invest early.

The expected late investment activity is an increasing function of the difference $k_{11}-k_{21}=\epsilon[1-\alpha-(2-\tau) x+\sqrt{D}]$. Differentiating gives

$$
\frac{\partial\left(k_{11}-k_{21}\right)}{\partial \phi}=\epsilon\left\{4 \epsilon-\frac{1}{2 \sqrt{D}}\left[16 s+32 \epsilon^{2}(2-\phi)\right]\right\} .
$$

Evaluating the above at $s=\bar{s}$ shows that

$$
\left.\frac{\partial\left(k_{11}-k_{21}\right)}{\partial \phi}\right|_{s=\bar{s}}=-\frac{16 \bar{s}}{(2-\phi) 8 \epsilon}<0 .
$$

Hence the expected second period investment activity is decreasing in $\delta$ for $s$ less but sufficiently close to $\bar{s}$. Q.E.D. 


\section{References}

Angeletos, G.-M., C. Hellwig and A. Pavan "Information, Coordination and Dynamics of Currency Crises," mimeo, forthcoming

Bryant, J. "A Simple Rational Expectations Keynes-Type Model," Quarterly Journal of Economics, August 1983, 525-528

Carlsson, H. and E. van Damme "Global Games and Equilibrium Selection," Econometrica, September 1993, 989-1018

Chamley, C. "Coordinating Regime Switches," Quartely Journal of Economics, August 1999, 869-905

Cole, H. and T. Kehoe "Self-fulfilling Debt Crises," Federal Reserve Bank of Minneapolis Staff Report 211

Corsetti, G., A. Dasgupta, S. Morris, and H. S. Shin "Does One Soros Make a Difference? A Theory of Currency Crises with Large and Small Traders," mimeo, August 2000

Dasgupta, A. "Coordination, Learning and Delay," mimeo, December 2001

Diamond, D. and P. Dybvig "Bank Runs, Deposit Insurance, and Liquidity," Journal of Political Economy, March 1983, 91, 401-419

Dönges, J. and F. Heinemann "Competition for Order Flow as a Coordination Game," mimeo, June 2000

Frankel, D., S. Morris and A. Pauzner "Equilibrium Selection in Global Games with Strategic Complementarities," Journal of Economic Theory, forthcoming.

Frankel, D. and A. Pauzner "Resolving Indeterminacy in Dynamic Settings: The Role of Shocks," Quartely Journal of Economics, 115, 2000, 285-304

Goldstein, I. and A. Pauzner "Demand Deposit Contracts and the Probability of Bank Runs," mimeo, April 2000

Milgrom, P. and J. Roberts "Rationalizability, Learning, and Equilibrium in Games with Strategic Complementarities," Econometrica, November 1990, 12551277.

Morris, S. and H. S. Shin "Global Games: Theory and Applications," mimeo, 2001

Morris, S. and H. S. Shin "The CNBC Effect: Welfare Effects of Public Information," mimeo, 2001

Morris, S. and H. S. Shin "A Theory of the Onset of Currency Attacks," in, Asian Financial Crisis: Causes, Contagion and Consequences, Agenon, Vines and Weiber Eds., Cambridge University Press 
Obstfeld, M. "Models of Currency Crises with Self-Fulfilling Features," European Economic Review, 40, 1996, 1037-1047

Postlewaite, A. and X. Vives "Bank Runs as an Equilibrium Phenomenon," Journal of Political Economy, 1987, 95, 485-491

Rochet, J.-C. and X. Vives "Coordination Failures and the Lender of Last resort: Was Bagehot Right After All?" mimeo, IAE, 2000

Rubinstein, A. "The Electronic Mail Game: Strategic Behavior Under "Almost Common Knowledge"," American Economic Review, 1989, 79, 385-391

Toxvaerd, F. "Strategic Merger Waves: A Theory of Musical Chairs" mimeo, December 2002 
Figure 1: Graphical representation of the mass of players investing in the two periods as a function of $\left(\mathrm{k}_{1}, \mathrm{k}_{2}\right)$.

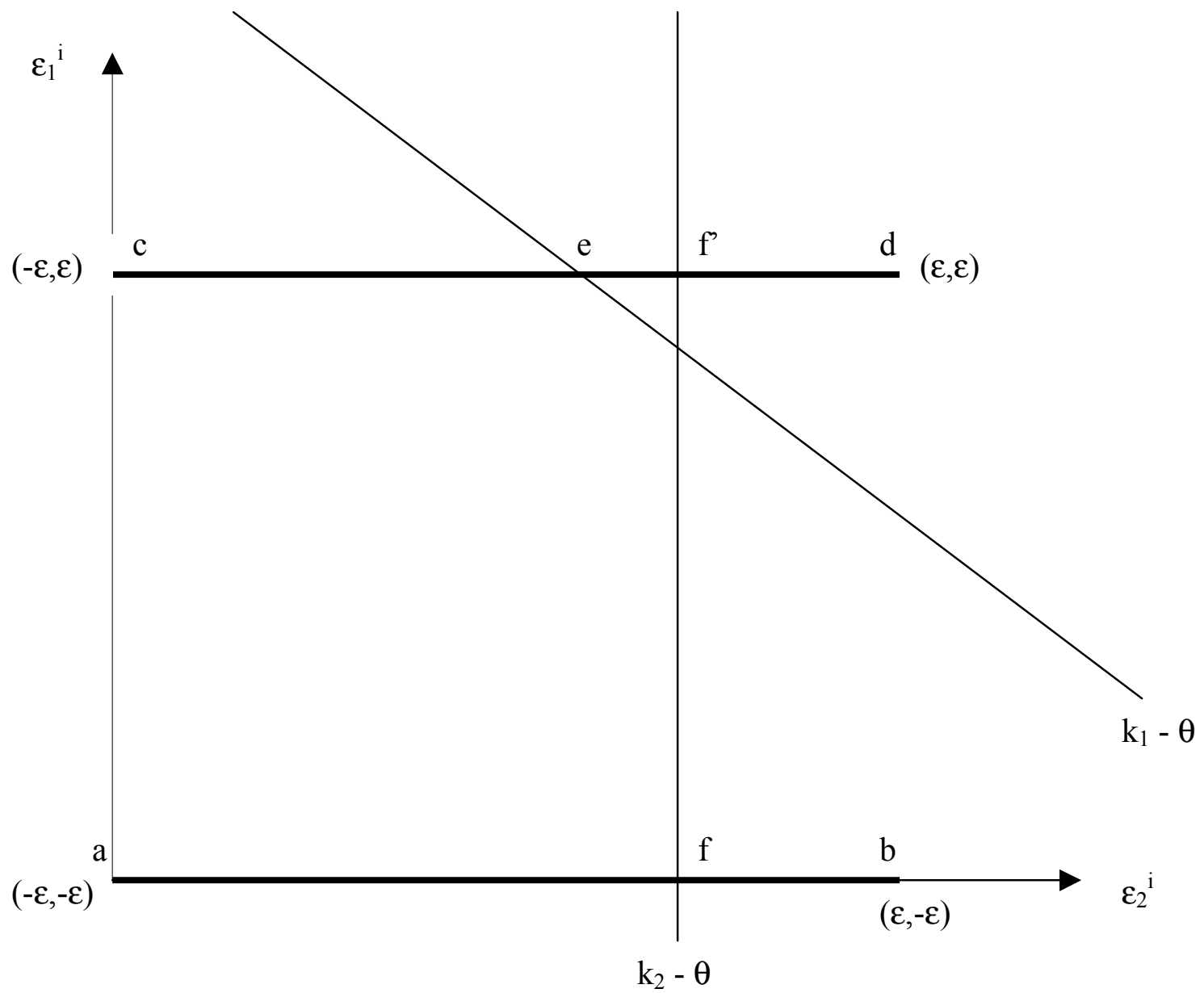


Figure 2: Graphical representation of the mass of players investing in the two periods as a function of $\left(\mathrm{k}_{1}, \mathrm{k}_{2}\right)$.

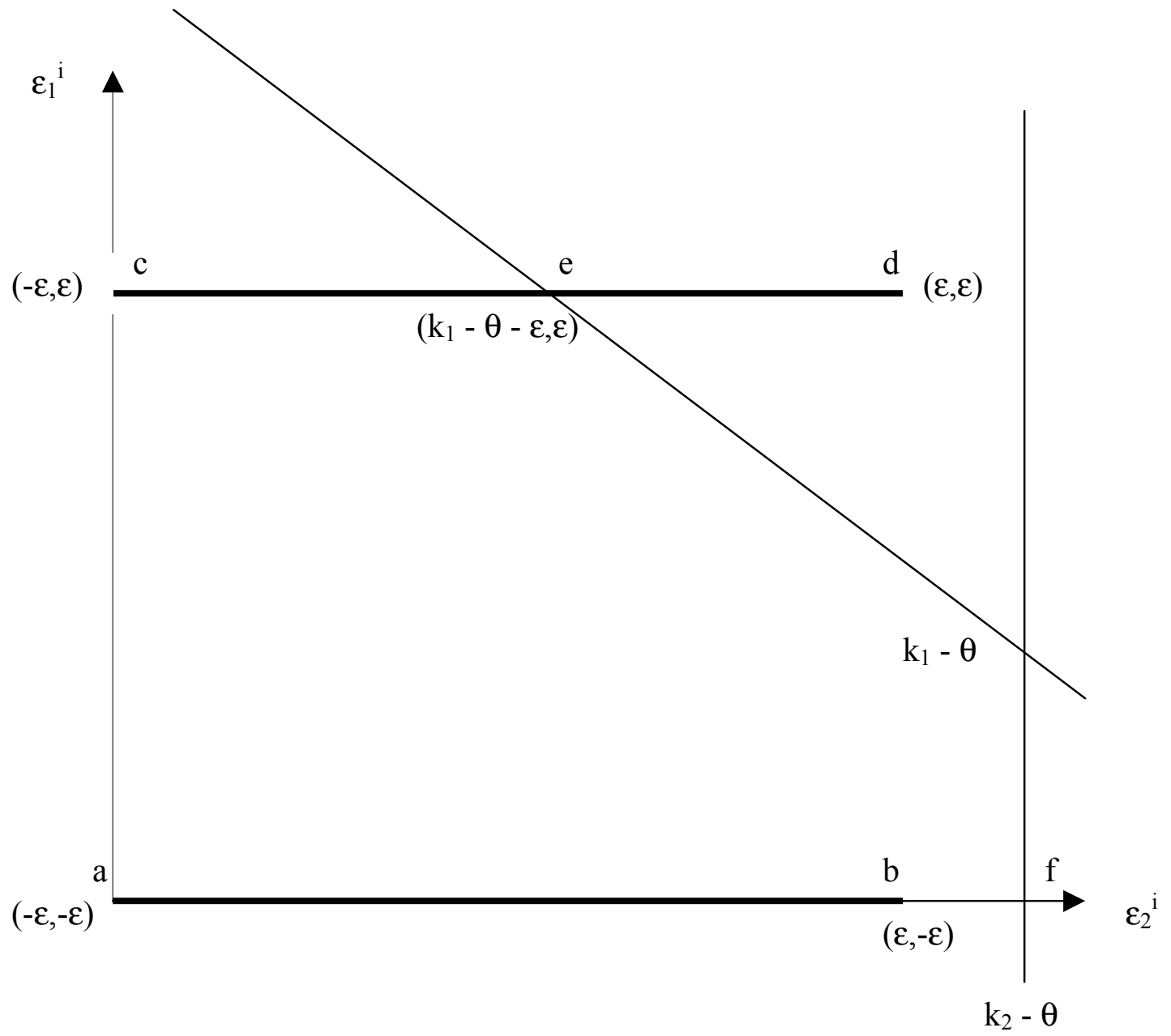


Figure 3: Graphical representation of the mass of players investing in the two periods as a function of $\left(\mathrm{k}_{1}, \mathrm{k}_{2}\right)$.

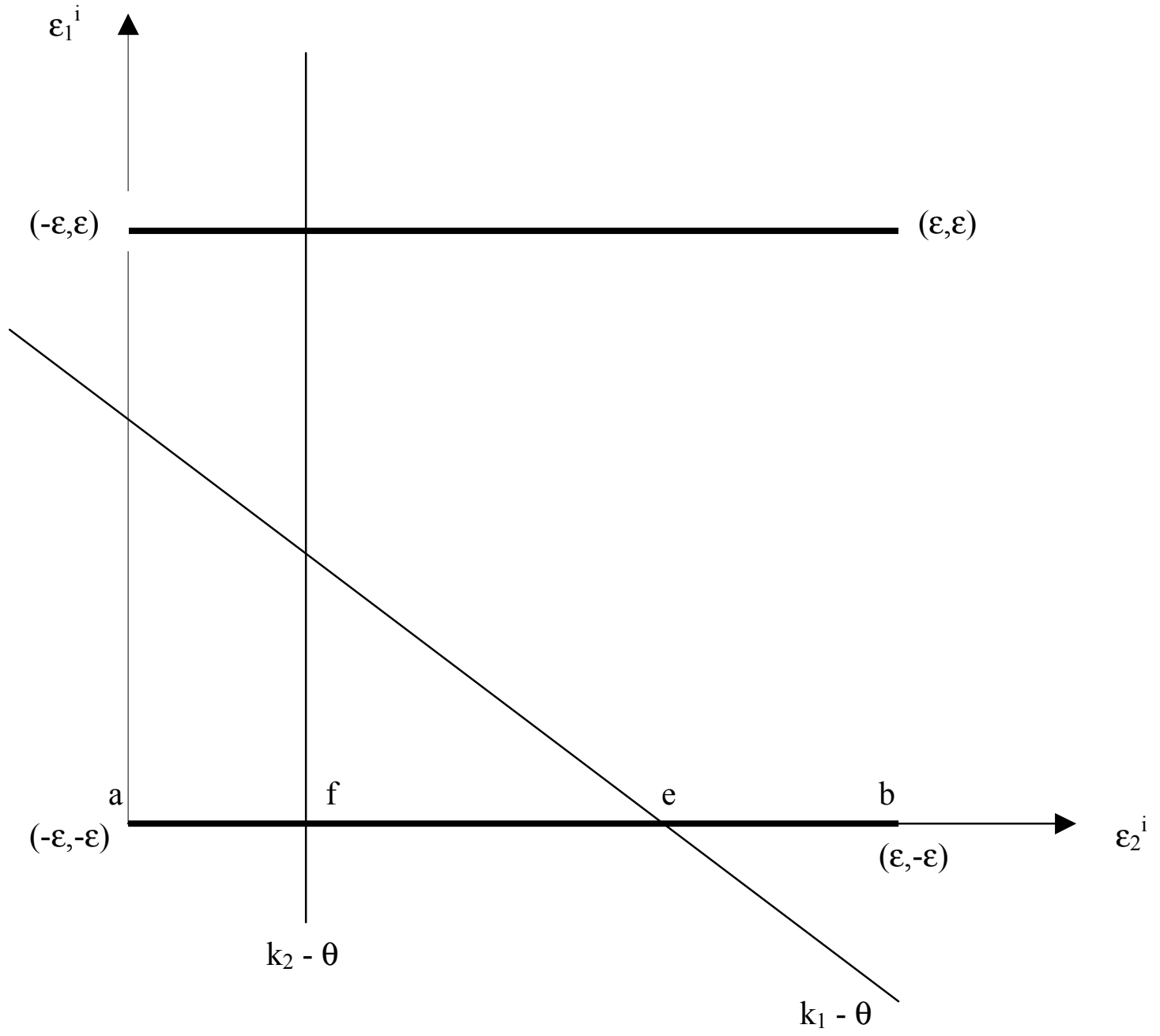



Bücher des Forschungsschwerpunkts Markt und politische Ökonomie

Books of the Research Area Markets and Political Economy

Andreas Stephan

Essays on the Contribution of Public Infrastructure to Private: Production and its Political

Economy

2002, dissertation.de

Hans Mewis

Essays on Herd Behavior and Strategic

Delegation

2001, Shaker Verlag

Andreas Moerke

Organisationslernen über Netzwerke - Die

personellen Verflechtungen von

Führungsgremien japanischer

Aktiengesellschaften

2001, Deutscher Universitäts-Verlag

Silke Neubauer

Multimarket Contact and Organizational Design

2001, Deutscher Universitäts-Verlag

Lars-Hendrik Röller, Christian Wey (Eds.)

Die Soziale Marktwirtschaft in der neuen

Weltwirtschaft, WZB Jahrbuch 2001

2001, edition sigma

Michael Tröge

Competition in Credit Markets: A Theoretic

Analysis

2001, Deutscher Universitäts-Verlag

Tobias Miarka

Financial Intermediation and Deregulation:

A Critical Analysis of Japanese Bank-Firm-

Relationships

2000, Physica-Verlag

Rita Zobel

Beschäftigungsveränderungen und organisationales Lernen in japanischen Industriengesellschaften

2000, Humboldt-Universität zu Berlin

http://dochost.rz.hu-berlin.de/dissertationen/zobel-

rita-2000-06-19

Jos Jansen

Essays on Incentives in Regulation and Innovation

2000, Tilburg University

Ralph Siebert

Innovation, Research Joint Ventures, and

Multiproduct Competition

2000, Humboldt-Universität zu Berlin

http://dochost.rz.hu-berlin.de/dissertationen/siebert-

ralph-2000-03-23/

Damien J. Neven, Lars-Hendrik Röller (Eds.)

The Political Economy of Industrial Policy in

Europe and the Member States

2000, edition sigma
Jianping Yang

Bankbeziehungen deutscher Unternehmen: Investitionsverhalten und Risikoanalyse 2000, Deutscher Universitäts-Verlag

Christoph Schenk

Cooperation between Competitors -

Subcontracting and the Influence of Information, Production and Capacity on Market Structure and Competition

1999, Humboldt-Universität zu Berlin

http://dochost.rz.hu-berlin.de/dissertationen/schenk-

christoph-1999-11-16

Horst Albach, Ulrike Görtzen, Rita Zobel (Eds.)

Information Processing as a Competitive

Advantage of Japanese Firms

1999, edition sigma

Dieter Köster

Wettbewerb in Netzproduktmärkten

1999, Deutscher Universitäts-Verlag

Christian Wey

Marktorganisation durch Standardisierung: Ein

Beitrag zur Neuen Institutionenökonomik des

Marktes

1999, edition sigma

Horst Albach, Meinolf Dierkes, Ariane Berthoin Antal, Kristina Vaillant (Hg.)

Organisationslernen - institutionelle und

kulturelle Dimensionen

WZB-Jahrbuch 1998

1998, edition sigma

Lars Bergman, Chris Doyle, Jordi Gual, Lars

Hultkrantz, Damien Neven, Lars-Hendrik Röller,

Leonard Waverman

Europe's Network Industries: Conflicting

Priorities - Telecommunications

Monitoring European Deregulation 1

1998, Centre for Economic Policy Research

Manfred Fleischer

The Inefficiency Trap

Strategy Failure in the

German Machine Tool Industry

1997, edition sigma

Christian Göseke

Information Gathering and Dissemination

The Contribution of JETRO to

Japanese Competitiveness

1997, Deutscher Universitäts-Verlag 

Fredrik Andersson

Kai A. Konrad

Lars-Hendrik Röller

Christian Wey

Talat Mahmood Klaus Schömann

Talat Mahmood Klaus Schömann

Jos Jansen

Jos Jansen

Günter Franke Harris Schlesinger Richard C. Stapleton

Tomaso Duso

Johan Lagerlöf

Paul Heidhues

Olivier Cadot Lars-Hendrik Röller Andreas Stephan

Justus Haucap

Christian Wey

Heidrun C. Hoppe Emre Ozdenoren

Rainer Nitsche

Daniel Krähmer

J. Peter Murmann

Kai A. Konrad

Robert Nuscheler

Fredrik Andersson Kai A. Konrad
Human Capital Investment and Globalization in Extortionary States

Merger Control in the New Economy

Die Determinanten der Mirgrationsentscheidung von IT-Hochschulabsolventen aus Pakistan Empirische Befunde zur Ausgestaltung der deutschen „Green Card“

The Determinants of the Migration Decision of ITgraduates from Pakistan: Empirical Evidence for the Design of a German "Green Card"

The Effects of Disclosure Regulation on Innovative Firms: Common Values

The Effects of Disclosure Regulation on Innovative Firms: Private Values

Multiplicative Background Risk

On the Politics of the Regulatory Reform:

Econometric Evidence from the OECD Countries

On the Desirability of an Efficiency Defense in

Merger Control

Contribution to Productivity or Pork Barrel? The Two Faces of Infrastructure Investment

Unionization Structures and Firms' Incentives for Productivity Enhancing Investments

Intermediation in Innovation

On the Effectiveness of Anti-Predation Rules

Entry and Experimentation in

Oligopolistic Markets for Experience Goods

The Coevolution of Industries and National Institutions: Theory and Evidence

Terrorism and the State

Physician Reimbursement, Time-Consistency and the Quality of Care

Taxation and Education Investment in the Tertiary Sector
FS IV $02-06$

FS IV $02-11$

FS IV $02-12$

FS IV $02-15$

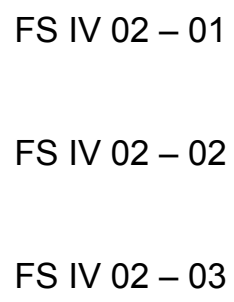

FS IV $02-02$ 
Jan Boone

Kai A. Konrad

Helmut Bester

Kai A. Konrad

Kjell Erik Lommerud Bjørn Sandvik

Odd Rune Straume

Steffen Huck Vicki Knoblauch Wieland Müller

Ralph Siebert

Jürgen Bracht

Saul Lach

Eyal Winter

Steffen Huck

Kai A. Konrad

Daniel Krähmer

Thomas Knaus

Robert Nuscheler

Kurt R. Brekke

Robert Nuscheler

Odd Rune Straume

Kai A. Konrad

Sebastian Kessing

Sebastian Kessing

Michal Grajek

Robert M. Adams Lars-Hendrik Röller

Robin C. Sickles

Tomaso Duso

Damien J. Neven Lars-Hendrik Röller

Tomaso Duso Astrid Jung
'Be nice, unless it pays to fight': A New Theory of

Price Determination with Implications for

Competition Policy

Altruism and Envy in Contests:

An Evolutionarily Stable Symbiosis

Delay in Contests

Good Jobs, Bad Jobs and Redistribution

On the Profitability of Collusion in Location Games

Learning by Doing and Multiproduction Effects over the Life Cycle: Evidence from the

Semiconductor Industry

Modeling Oligopolistic Price Adjustment in Micro

Level Panel Data

Strategic Trade Policy and the Home Bias in Firm

Ownership Structure

Delegation versus Authority

Incomplete Risk Adjustment and Adverse

Selection in the German Public Health Insurance System

Quality and Location Choices under Price

Regulation

Inverse Campaigning

A Note on the Determinants of Labour Share Movements

Employment Protection and Product Market Competition

Identification of Network Externalities in Markets for Non-Durables

Market Power in Outputs and Inputs: An Empirical Application to Banking

The Political Economy of European Merger Control: Evidence using Stock Market Data

Market Conduct and Endogenous Lobbying: Evidence from the U.S. Mobile Telecommunications Industry
FS IV $02-20$

FS IV $02-21$

FS IV $02-22$

FS IV $02-28$

FS IV $02-29$

FS IV $02-18$

FS IV $02-19$

FS IV $02-23$

FS IV $02-24$

FS IV $02-25$

FS IV $02-26$

FS IV $02-27$

FS IV $02-30$

FS IV $02-31$

FS IV $02-32$

FS IV $02-33$

FS IV $02-34$

FS IV $02-35$ 
Annette Boom

Kai A. Konrad Wolfram F. Richter

Stergios Skaperdas

Johan Lagerlöf

Roman Inderst Christian Wey

Sebastian Kessing Robert Nuscheler

Lars Frisell

Paul Heidhues Nicolas Melissas
Investments in Electricity Generating Capacity under Different Market Structures and with Endogenously Fixed Demand

Zur Berücksichtigung von Kindern bei umlagefinanzierter Alterssicherung

Restraining the Genuine Homo Economicus: Why the Economy cannot be divorced from its Governance

Insisting on a Non-Negative Price: Oligopoly, Uncertainty, Welfare, and Multiple Equilibria

Buyer Power and Supplier Incentives

Monopoly Pricing with Negative Network Effects: the Case of Vaccines

The Breakdown of Authority

Equilibria in a Dynamic Global Game: The Role of Cohort Effects
SP || $2003-05$

SP || $2003-07$

SP || $2003-01$

SP || $2003-02$

SP || $2003-03$

SP || $2003-04$

SP || $2003-06$

SP || $2003-08$ 
Bei Ihren Bestellungen von WZB-Papers schicken

Sie bitte unbedingt einen an Sie adressierten Auf-

kleber mit sowie je paper eine Briefmarke im Wert

von 0,51 Euro oder einen "Coupon Reponse Inter-

national " (für Besteller aus dem Ausland)
Please send a self addressed label and postage stamps in the amount of 0.51 Euro or a "CouponReponse International" (if you are ordering from outside Germany) for each WZB-paper requested

Absender / Return Address:

Wissenschaftszentrum Berlin

für Sozialforschung

Presse- und informationsreferat

Reichpietschufer 50

D-10785 Berlin-Tiergarten

Hiermit bestelle ich folgende(s)

Discussion paper(s):

Please send me the following Discussion paper(s):

Bestell-Nr. / Order no.

Autor/in, Kurztitel /Author(s) / Title(s) in brief 